OPEN ACCESS

Edited by:

Philippe Musette,

Centre Hospitalier Universitaire (CHU)

de Rouen, France

Reviewed by: Takashi Hashimoto,

Osaka University, Japan

Irina Khamaganova,

Pirogov Russian National Research

Medical University, Russia

${ }^{*}$ Correspondence:

Mareike Witte

mareike.witte@uksh.de

Specialty section:

This article was submitted to

Dermatology,

a section of the journal

Frontiers in Medicine

Received: 11 July 2018 Accepted: 05 October 2018 Published: 02 November 2018

Citation:

Witte M, Zillikens $D$ and Schmidt $E$ (2018) Diagnosis of Autoimmune

Blistering Diseases.

Front. Med. 5:296.

doi: 10.3389/fmed.2018.00296

\section{Diagnosis of Autoimmune Blistering Diseases}

\author{
Mareike Witte*, Detlef Zillikens and Enno Schmidt \\ Department of Dermatology, University of Lübeck, Lübeck, Germany
}

Autoimmune skin blistering diseases (AIBD) are characterized by autoantibodies that are directed against structural proteins in the skin and adjacent mucous membranes. Some clinical signs are typical for a specific AIBD, however, correct diagnosis requires the detection of tissue-bound or circulating autoantibodies. The gold standard for diagnosis of AIBD is the detection of autoantibodies or complement component 3 by direct immunofluorescence (DIF) microscopy of a perilesional biopsy. Circulating antibodies can be detected via indirect immunofluorescence (IIF) microscopy of different tissue substrates including human skin, monkey esophagus, and more recently, recombinant forms of the different target antigens. Latter are also employed in various commercial ELISA systems and by immunoblotting in in-house assays available in specialized laboratories. ELISA systems are also particularly valuable for monitoring of the disease activity during the disease course which can be helpful for treatment decisions. Exact diagnosis is essential for both treatment and prognosis, since some AIBD are associated with malign tumors such as paraneoplastic pemphigus and anti-laminin 332 mucous membrane pemphigoid. This review presents clinical and immunopathological features of AIBD for the state-of the art diagnosis of these disorders.

Keywords: autoantibody, biochip, immunofluorescence, ELISA, pemphigus, pemphigoid, epidermolysis bullosa acquisita, dermatitis herpetiformis

\section{INTRODUCTION}

Autoimmune skin blistering diseases (AIBD) are a diverse group of dermatoses that are characterized by autoantibodies binding to antigens in the skin and mucous membranes. They can be subdivided into pemphigoid diseases (PD), with subepidermal split formation and autoantibody binding to structural components of the dermal-epidermal junction (DEJ), and pemphigus, with autoantibodies directed against desmosomal proteins that connect neighboring keratinocytes $(1,2)$. A special type of AIBD is dermatitis herpetiformis, with autoantibodies directed against the tissue and epidermal transglutaminase. In this review, we will provide a comprehensive overview about the clinical features and current diagnosis of AIBD extending and updating previous work $(3,4)$.

\section{EPIDEMIOLOGY}

Bullous pemphigoid (BP) is the most frequent AIBD in Central Europe. Its incidence reaches around 20/million/year. BP is followed by mucous membrane pemphigoid (MMP) and pemphigoid gestationis, with incidences of $2 /$ million/year, respectively (5-8). Higher incidences of BP have been reported in Great Britain (9). In contrast to other autoimmune diseases, the incidence of $\mathrm{BP}$ is increasing with age. Regarding this matter, its annual incidence in people older than 80 
years reaches 150-180/million/year (5, 6). Like other autoimmune diseases, the incidence of BP is constantly increasing and has nearly doubled in the last decade (7-11). This is partly due to the rising life expectancy of the general population, increasing awareness, and enhanced diagnostic tests. Further, the close association between BP and neurological diseases [reviewed in (12)], whose incidences are also rising, may contribute to the increased occurrence of BP. This rise in BP incidence is reflected by hospitalization numbers of BP patients that increased by $26 \%$ for a primary diagnosis and by $62 \%$ for a secondary diagnosis to 3,260 /million inpatients between 2002 and 2012 in the USA (13).

In pemphigus, the incidence depends on the geographical region. In Central Europe and the United States, its incidence is estimated between 1 and 7 new patients/million/year $(9,14)$. Generally, PV is more common than pemphigus foliaceus (PF), with ratios ranging from 4:1 to 9:1 (15). In Tunisia and Brazil, endemic forms of PF with much higher incidences are present $(16,17)$.

The prevalence of AIBD in Germany have recently been calculated based on the ICD-coding-based dataset of the country's largest health insurance. The study revealed about 40,000 AIBD patients including 21,000 patients with BP, 7,700 with PV, and around 2,000 with MMP (18).

\section{HISTORICAL BACKGROUND}

The term pemphigus was first used by Hippocrates in 460370 B.C. (19). However, the differentiation between pemphigus and BP was first made by Walter Lever in 1953 based on lesional histopathology (20). In 1964 and 1967, detection of autoantibodies in serum and skin were reported for pemphigus and $\mathrm{BP}(21,22)$, providing milestones for the diagnosis of AIBD. Diagnosis of the different AIBD entities became subsequently possible by the molecular identification of target antigens (23). In parallel it became clear that the autoantibodies used for the diagnosis of AIBDs may be directly pathogenic (24-29), reviewed in $(1,30-34)$.

\section{DIRECT IMMUNOFLUORESCENCE MICROSCOPY}

The diagnosis of AIBDs is based on the combination of the clinical presentation and detection of tissue-bound and/or circulating autoantibodies. Tissue-bound autoantibodies can be detected via direct immunofluorescence (DIF) microscopy, which is the diagnostic gold standard for AIBD. For DIF microscopy, cryosections of perilesional biopsies are required and need to be snap frozen and stored at $-20^{\circ} \mathrm{C}$ or conserved in isotonic $\mathrm{NaCl}$ or modified Michels medium until processed $(35,36)$.

DIF microscopy only provides limited information about the target antigen(s), however the diagnosis can be narrowed down according to the immunoglobulin subclass and binding pattern. In pemphigus, DIF microscopy reveals intercellular binding of IgG and/or C3 within the epidermis and/or epithelium. In pemphigoid diseases, a linear deposition of IgG and/or C3 at the DEJ can be observed (Figures 1, 2). Linear staining at the DEJ can further be differentiated into $n$-serrated and u-serrated patterns. In an $n$-serration pattern, arches are closed at the top (Figure 3 left) and in a u-serrated staining pattern, arches are closed at the bottom appearing like "growing grass" (Figure 3 right). While u-serration is unique for antibody binding to type VII collagen and can been seen in epidermolysis bullosa acquisita (EBA), n-serration is found in all other pemphigoid diseases (3739). Serration pattern analysis can be performed in any routine immunofluorescence (IF) laboratory and is best performed in $6 \mu \mathrm{m}$ sections and 400- or 600-fold magnification without oil $(38,39)$. IF pictures for training of serration pattern analysis are freely available (www.nversusu.umcg.nl).

In dermatitis herpetiformis, DIF microscopy reveals granular deposition of IgA at the dermal papillae and along the DEJ. An automated staining for DIF microscopy sections has recently been developed and revealed more intensive IF staining and reduced background compared to the manual procedure due to continuous movement and overhead incubation (40). A flowchart navigating through differential diagnoses using DIF microscopy is shown in Figure 1. For further differentiation of the target antigen(s) serological analyses is required.

\section{INDIRECT IMMUNOFLUORESCENCE MICROSCOPY USING TISSUE SUBSTRATES}

Several tissues can be employed by indirect IF (IIF) microscopy to screen for serum autoantibodies in AIBD including monkey, rabbit, guinea pig, and human esophagus (for pemphigus and pemphigoid diseases), monkey and rat bladder (for paraneoplastic pemphigus), and amnion epithelium (for BP and PV). In one study, monkey esophagus was the most sensitive substrate for pemphigus; another study showed that monkey esophagus is more sensitive for PV and human esophagus is more sensitive for PF (41-44). The most frequently used substrates are monkey esophagus and human split skin. On monkey esophagus, autoantibodies in pemphigus reveal intercellular labeling of the epithelium and linear staining of the DEJ in pemphigoid diseases (Figure 2). Sensitivities of $90 \%$ and $73.2 \%$ have been reported for pemphigus and BP, respectively $(41,43)$. In dermatitis herpetiformis, IgA binds to the endomysium. The tissue substrate with the highest sensitivity for autoantibodies in pemphigoid diseases is $1 \mathrm{M} \mathrm{NaCl}$ split human skin. Here, antibodies bind either to the epidermal ("roof") or dermal ("floor") side of the artificial blister (Figure 2, left and right panel, respectively). "Floor"-binding antibodies can be detected in EBA, anti-p200/laminin $\gamma 1$ pemphigoid, and anti-laminin 332 MMP. "Roof"-binding antibodies target BP180 and BP230 and are observed in BP, linear IgA-disease, pemphigoid gestationis, and anti-BP180-type mucous membrane pemphigoid. Sensitivities for BP range between 73 and $84 \%(41,45)$.

The most sensitive substrates for the detection of anti-plakin reactivity are monkey and rat bladder epithelium. In pemphigoid 


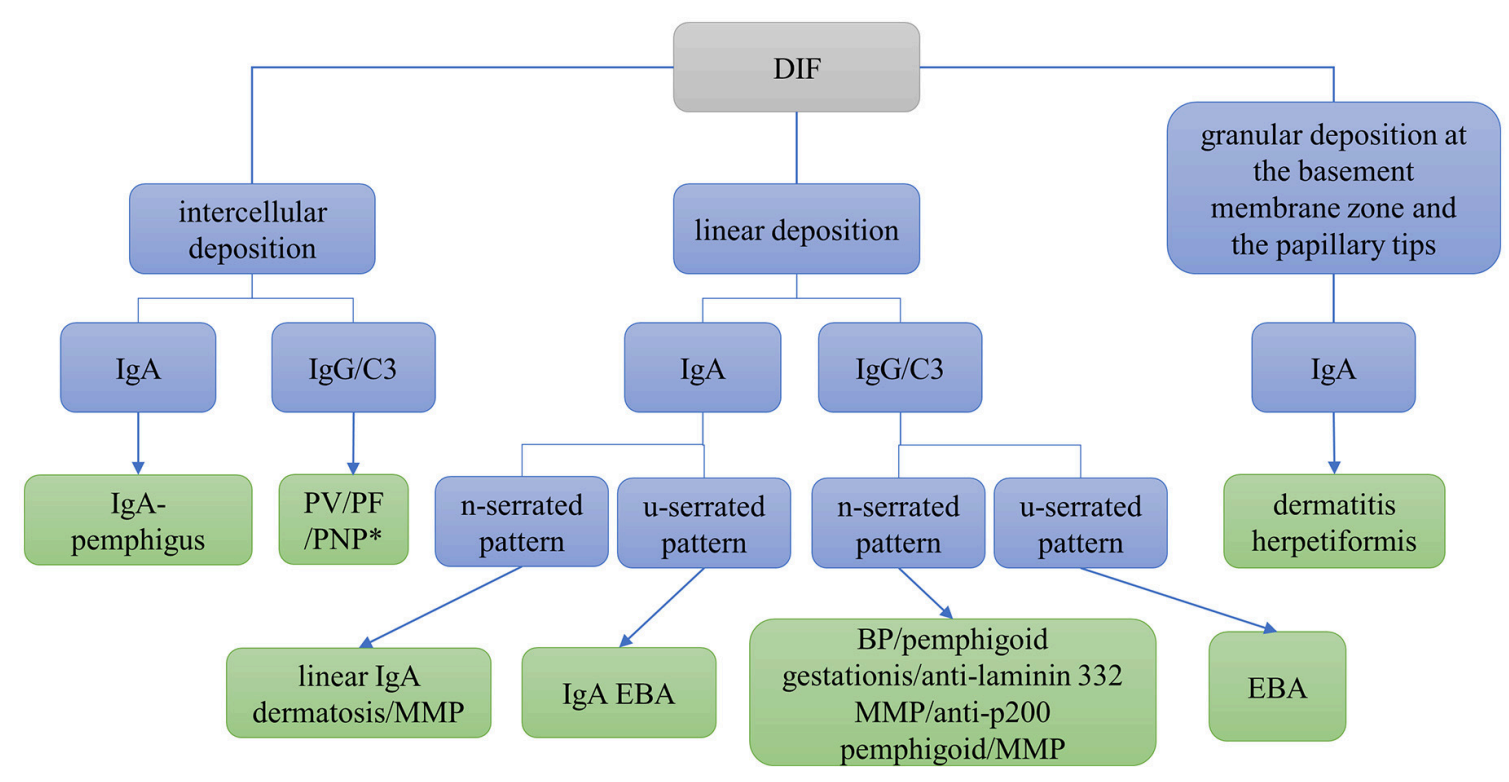

FIGURE 1 | Differential diagnosis of autoimmune skin blistering diseases based on direct immunofluorescence (DIF) microscopy of a perilesional biopsy. BP, bullous pemphigoid; EBA, epidermolysis bullosa acquisita; MMP, mucous membrane pemphigoid; PF, pemphigus foliaceus; PNP, paraneoplastic pemphigus; PV, pemphigus vulgaris; " may be combined with linear deposition.

gestationis, the complement fixation test detects complementfixing IgG on human salt-split skin. For definite diagnosis of most AIBD refined analysis of serum autoantibodies can be performed, employing recombinant or cell-derived antigens. A flowchart depicting the serological diagnosis of autoimmune blistering diseases is shown in Figure 4.

\section{TARGET ANTIGEN-SPECIFIC ANALYSIS OF SERUM AUTOANTIBODIES}

For the identification of the target antigen, three main systems have been described: (i) Enzyme-linked immunosorbent assay (ELISA), (ii) IIF microscopy, and (iii) immunoblot/immunoprecipitation.

(i) ELISA systems allow the identification and quantification of autoantibodies against specific autoantigens. They are applied for both diagnosis and monitoring of the activity of the disease during the disease process (46). For pemphigoid diseases, commercial ELISA systems include BP180 NC16A, BP230, and type VII collagen, which employ recombinant protein, respectively (MBL, Euroimmun) (47-52). The sensitivity of the BP180 NC16A ELISA ranges between 84 and $89 \%$ in BP $(47,49,53)$ and between 96 and 97\% in pemphigoid gestations $(54,55)$. The sensitivity in $\mathrm{BP}$ can be increased by the additional use of the BP230 ELISA by about $5 \%(52,56,57)$. For pemphigus, ELISA systems employ the ectodomains of Dsg1 and Dsg3 recombinantly expressed in HEK293 cells (Euroimmun) or baculovirus (MBL, Nagoya, Japan) (46, 58, 59). For paraneoplastic pemphigus, an ELISA system for autoantibodies against envoplakin has been developed
(Euroimmun) (60). For dermatitis herpetiformis, ELISA systems for the detection of coeliac-specific gliadin IgG and IgA autoantibodies as well as anti-transglutaminase 2 and 3 -antibodies are available (61). ELISA systems that are less standardized and only available in specialized laboratories include desmocollin $(62,63)$, laminin $\gamma 1(64,65)$, the ectodomain of BP180 (66), full-length BP180 (67), laminin 332 $(68,69)$ and BP180 NC16A-IgE-ELISA $(70-72)$ as well as other forms of $\mathrm{BP} 180(73,74)$.

In addition, two multivariant ELISA systems compiled of the individual assays include recombinant Dsg 1 and 3, BP180 NC16A, BP230, type VII collagen, and only in one system, envoplakin, are widely available $(75,76)$.

(ii) IIF-based assays employing recombinant forms of the target antigens are available as multivariant assays and thus, offer a single-step method for the diagnosis of AIBDs. These assays are based on the BIOCHIP ${ }^{\circledR}$ mosaic technology using normally-sized laboratory slides with 5-10 incubation fields. The serum sample is loaded onto an incubation field, consisting of several miniature biochips coated with different substrates (e.g., monkey esophagus, salt-split skin, recombinant BP180 NC16A or HEK293 cells recombinantly expressing Dsg1, Dsg3, or BP230). We have shown that the sensitivity and specificity of BIOCHIP ${ }^{\circledR}$ mosaic analysis is comparable to that of ELISA systems regarding AIBDs (77). Meanwhile, this technology has been applied in different routine laboratories worldwide (78-80). More recently, a mosaic comprising 4 biochips coated with recombinant BP180 NC16A, HEK cells expressing BP230, salt-split skin and monkey esophagus, respectively, showed a sensitivity 


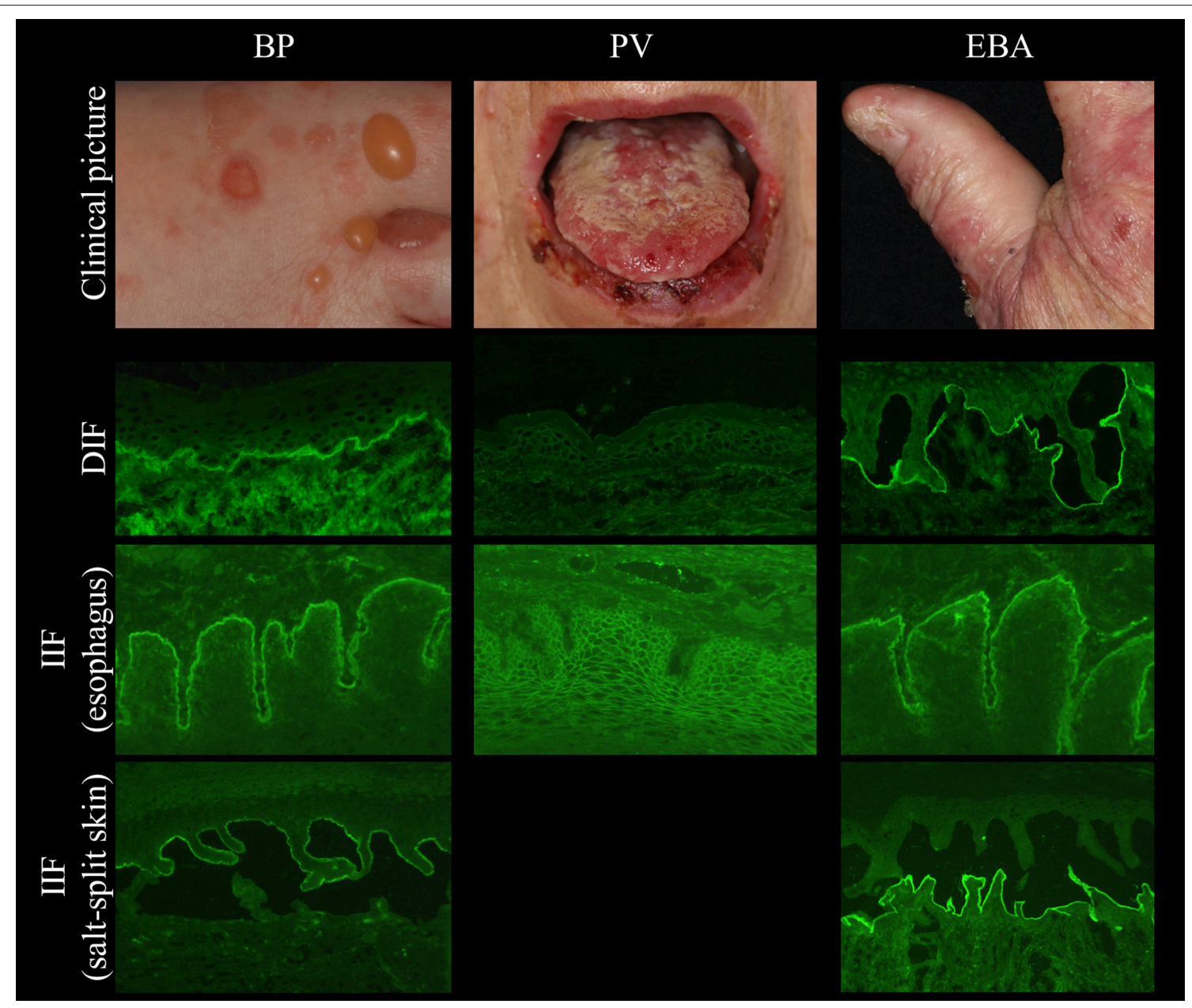

FIGURE 2 | Clinical and immunopathological characteristics in bullous pemphigoid (BP, left), pemphigus vulgaris (PV, middle), and epidermolysis bullosa acquisita (EBA, right).
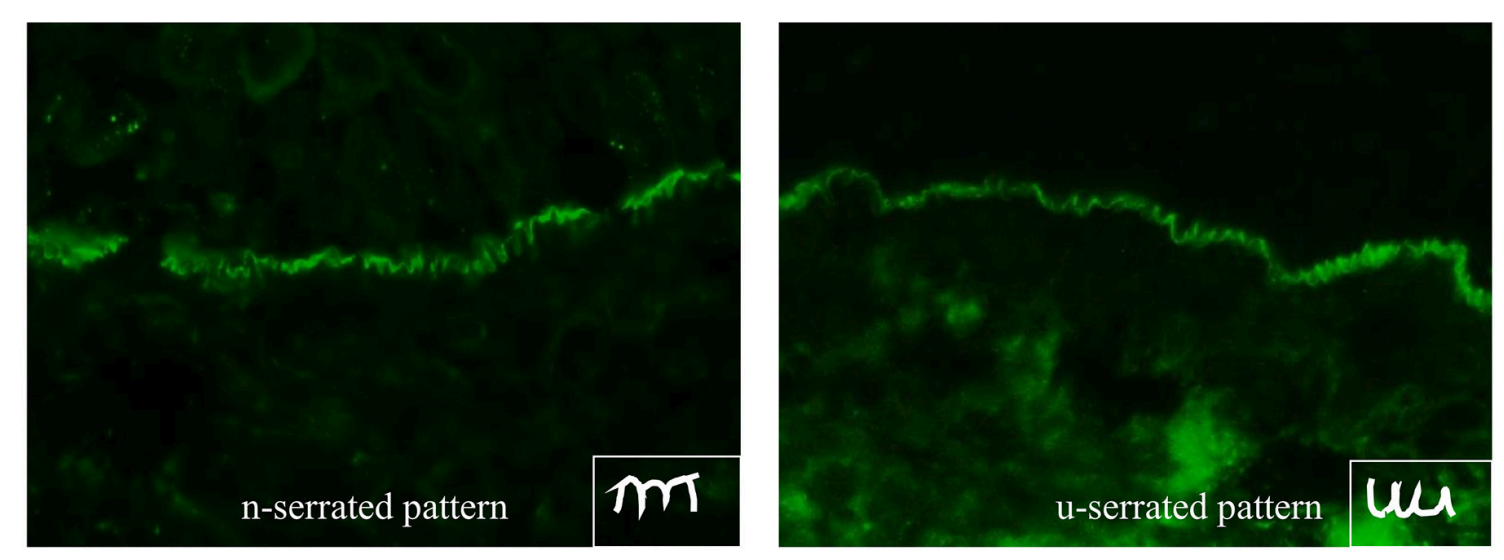

FIGURE 3 | n-serrated (left) and u-serrated pattern (right) of basement membrane zone staining in pemphigoid diseases detected by direct immunofluorescence microscopy. While an u-serrated pattern is exclusively seen in epidermolysis bullosa acquisita, an n-serrated pattern can be detected in all other pemphigoid diseases.

of $100 \%$ when testing with pemphigoid gestationis sera (79). A BIOCHIP ${ }^{\circledR}$ mosaic including the immunodominant NC1 domain of type VII collagen yielded sensitivities of 92 and $100 \%(50,81)$, indicating that BIOCHIP ${ }^{\circledR}$ technology is a valuable tool in the routine diagnosis of pemphigoid gestationis and EBA. As for desmocollins, anti-desmocollin 


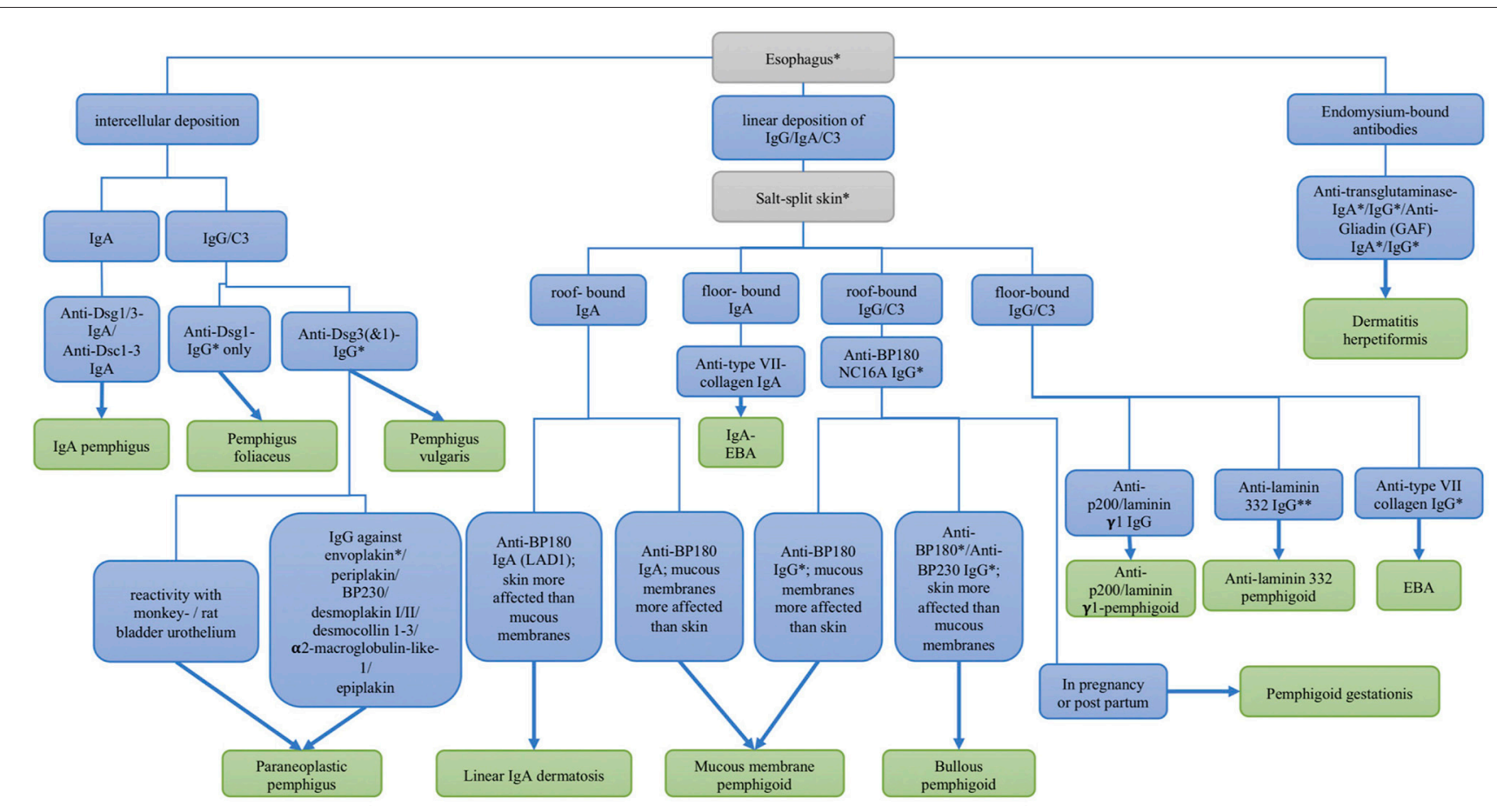

FIGURE 4 | Differential diagnosis of autoimmune skin blistering diseases based on the serological detection of autoantibodies. Dsc, desmocollin; Dsg, desmoglein; EBA, epidermolysis bullosa acquisita; * commercial assays are available; ** available by the end of 2018.

$\operatorname{IgG}$ and/or IgA reactivity was only found in about $3 \%$ of around 400 pemphigus sera, using a BIOCHIP $^{\circledR}$ mosaic containing recombinant forms of desmocollin $1,-2$, and -3 (82). Therefore, according to the guidelines of the German Dermatological Society, the analysis for anti-desmocollin reactivity is only recommended in patients with $\operatorname{IgA}$ pemphigus, pemphigus vegetans, atypical pemphigus, and the rare patients with pemphigus vulgaris/foliaceus without antiDsg reactivity (36). Most recently, a BIOCHIP ${ }^{\circledR}$ mosaic was developed containing recombinant chains of laminin 332 for the diagnosis of anti-laminin 332-pemphigoid (83) (Figure 5). This BIOCHIP ${ }^{\circledR}$ mosaic yields sensitivities between 75 and $85 \%$ with a specificity of nearly $100 \%$ (83).

(iii) Immunoblotting and immunoprecipitation are performed using recombinant proteins or extracts of dermis, epidermis, bovine gingiva, amnion membrane or cultured keratinocytes (80-86). These systems are part of the diagnostic algorithm for AIBD in some laboratories. They can be used for the detection of anti-p200 autoantibodies (Figure 6), anti-laminin $\gamma 1$ autoantibodies, antibodies against C-terminal stretches of BP180, and the soluble ectodomain of BP180 (LAD-1; Figure 7), as well as autoantibodies against cell-derived forms of envoplakin, periplakin, desmoplakin, BP180, BP230, $\alpha 4 \beta 6$-integrin, laminin 332, and type VII collagen (Figure 6) (87). Latter test systems are, however, only available in specialized laboratories including the autoimmune laboratory of the Department of Dermatology, Lübeck, Germany (88). The laboratory has been accredited by Deutsche Akkreditierungsstelle (DAkkS D-ML-13069-06-00) and is also involved in the development of novel assay systems (www.uksh.de/dermatologie-luebeck/Infos+für+Ärzte+und+ Einsender/Autoimmunlabor.html). The main diagnostic algorithm of our laboratory is shown in Figure 4 and further detailed in Schmidt et al. (3).

\section{DIAGNOSTICALLY RELEVANT CLINICAL AND IMMUNOPATHOLOGICAL CHARACTERISTICS OF MAJOR AIBD}

\section{Pemphigus Vulgaris and Pemphigus Foliaceus}

Pemphigus can be divided in two major clinical subtypes, PV and PF. Autoantibodies in pemphigus are directed against epidermal desmosomes, mainly desmoglein (Dsg) 1 and 3. A common clinical finding is a positive Nikolsky sign. Here, mechanical friction of perilesional skin results in exfoliation of the outermost skin layer. The Nikolsky sign moderately sensitive, but highly specific in the diagnosis of pemphigus (89). PF is clinically characterized by flaccid, superficial erosions preferentially in seborrheic areas. The erosions are usually covered by scaling, which is due to the detachment of the superficial layers of the epidermis (90). In PF, mucous membranes are completely spared (3). Autoantibodies in PF are directed against Dsg1 and can be detected by ELISA or IIF microscopy $(46,88,91$ ) (Figure 4$)$. In nearly all PF patients, anti-Dsg1 serum levels closely correlate with disease activity (46). 

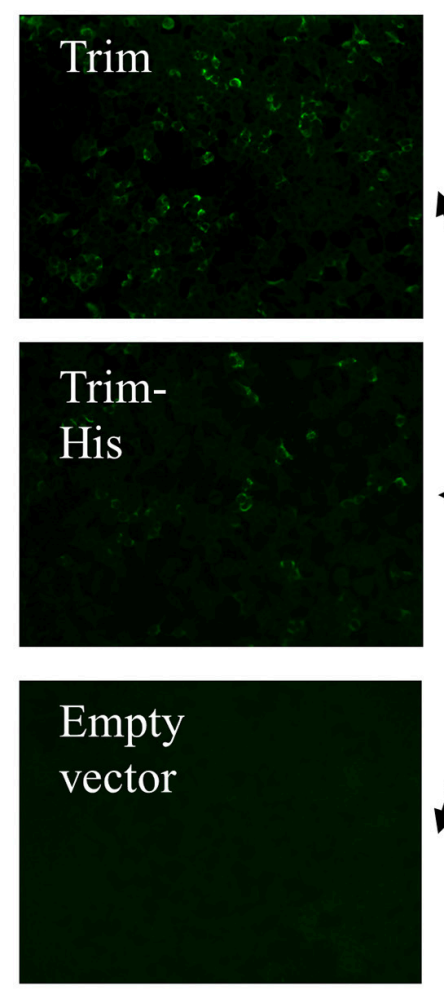
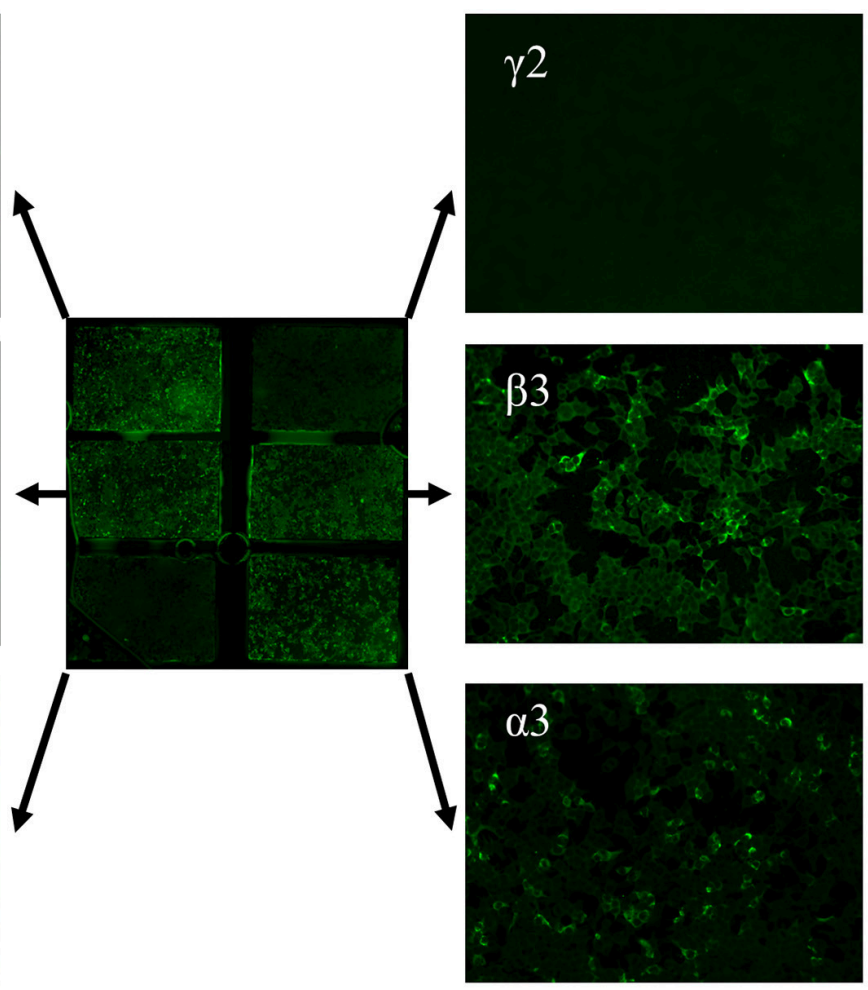

FIGURE 5 | Anti-laminin 332 BIOCHIP ${ }^{\circledR}$ mosaic. The mosaic contains HEK293 cells expressing the recombinant laminin 332 heterotrimer (Trim; upper left and middle left), the recombinant $\gamma 2$ - $\mathrm{t} \beta 3$-, and $\alpha 3$-chains of laminin 332 as well as negative control, cells transfected with the empty vector. Here, antibody binding is seen with the heterotrimer and the $\beta 3$ - and $\alpha 3$-chains in a patient with anti-laminin 332 mucous membrane pemphigoid.

In contrast to PF, patients with PV always suffer from mucous membrane lesions (Figure 2 middle). These are accompanied to a variable extent with blisters and/or erosions of the skin. Autoantibodies in PV are directed against Dsg 3 (92). When in addition to mucosal involvement, lesions are also present on the skin, patients with PV also have autoantibodies against Dsg1 (1). According to the extent of affected skin, three types of PV can be distinguished: (i) the mucosal-dominant type with limited cutaneous involvement (Dsg 3-autoantibodies are predominant), (ii) the mucocutaneous type with both mucosal and cutaneous involvement (Dsg3- and Dsg1-autoantibodies are equally predominant) and the cutaneous type with predominant anti-Dsg1 and pathogenically weak anti-Dsg3 autoantibodies (1). Alike Dsg1-specific autoantibodies, anti-Dsg3-autoantibodies can be detected by ELISA (46). Both Dsg1- and 3-autoantibody levels correlate with the disease activity and can therefore be used as disease activity marker $(30,46)$.

\section{Paraneoplastic Pemphigus}

Paraneoplastic pemphigus (PNP) is an AIBD that is characterized by its association with malignant (or rarely benign) neoplasms. The most frequently associated neoplasms are B-cell lymphoma, Castleman disease, chronic lymphocytic leukemia, thymoma, and Waldenstrom macroglobulinemia $(84,93,94)$. The clinical phenotype is diverse. First, PNP mainly affects the oral mucosa with other mucous membranes less frequently involved (95-97).
Cutaneous lesions may arise on any part of the skin and may include: (i) pemphigus-like lesions with flaccid blisters, erosions, erythema and crusts; (ii) BP-like lesions such as urticarial lesions and tense blisters (96); (iii) erythema multiforme-like lesions and (iv) lichen planus-like lesions presenting as flat scaly papules and intense mucous membrane involvement (95). Furthermore, pulmonary destruction leading to bronchiolitis obliterans was noticed in many PNP-patients (98).

Apart from Dsg3, the autoantibodies may be directed against plakins such as BP230, periplakin, envoplakin, desmoplakin 1 and 2, and plectin (84). More recently, antibodies against desmocollins, $\alpha 2$ macroglobulin-like 1, and epiplakin have been described $(62,99,100)$ (Figure 4). Antibodies against envoplakin and periplakin are most frequent $(60,101,102)$. They can be detected via Western blotting or immunoprecipitation of extracts from keratinocytes (84), and, more conveniently, by a commercial ELISA employing the recombinant $\mathrm{N}$-terminus of envoplakin (60).

\section{Bullous Pemphigoid}

In $\mathrm{BP}$, autoantibodies are directed against a $180 \mathrm{kDa}$-sized (BP180/BPAG2/XVII collagen) and/or a $230 \mathrm{kDa}$-sized (BP230/BPAG1) antigen, which are essential for dermalepidermal adhesion (103) (Figure 2 left). The disease is mainly diagnosed in people aged between 75 and 80 years (18). It rarely occurs in people under the age of 50 years with few children 


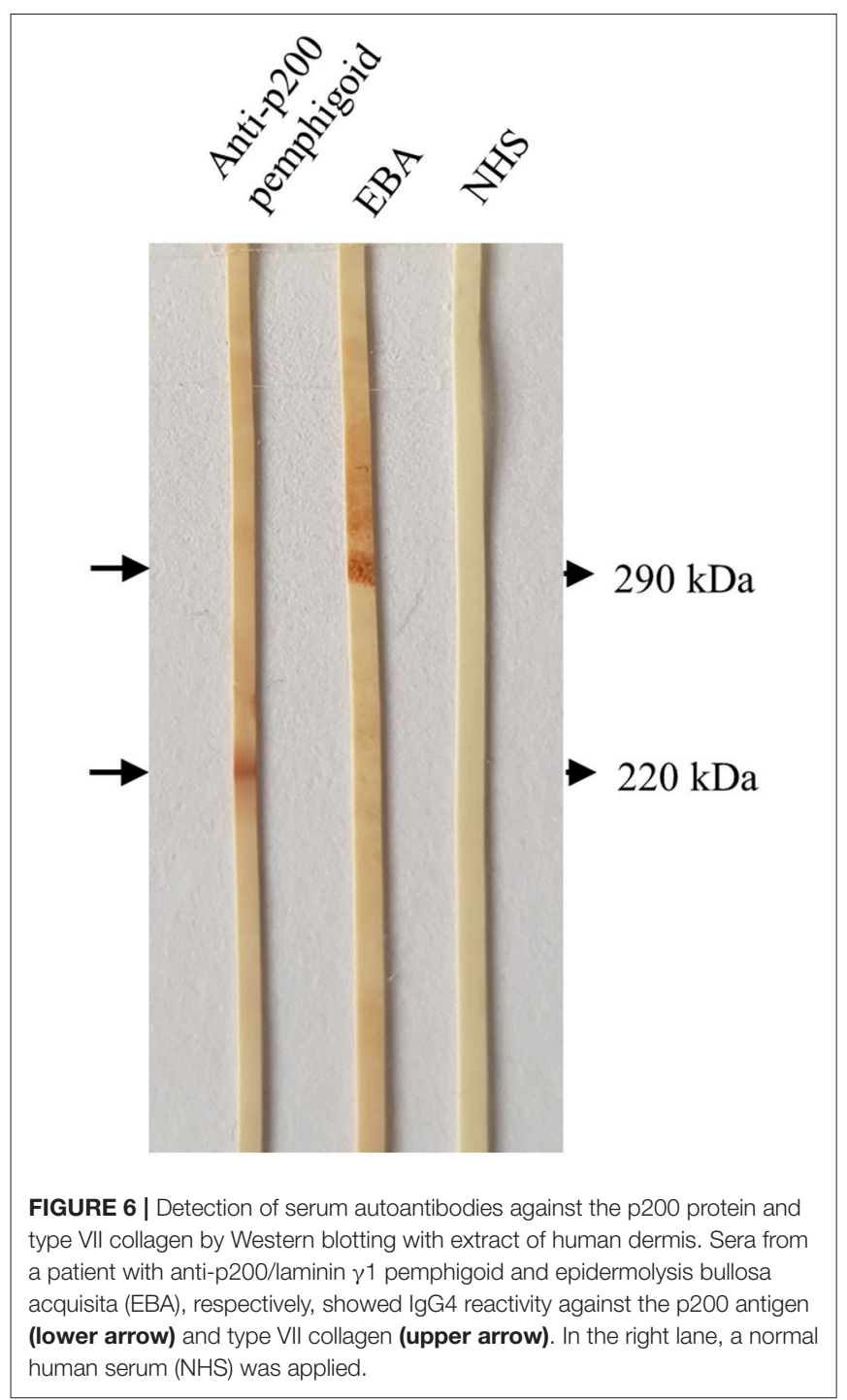

described with BP (104). In nearly all patients with BP, intense pruritus is present (105). Classically, BP presents with tense blisters and erosions. In contrast to pemphigus, the Nikolsky sign is negative. Alternatively or additionally, urticarial and erythematous non-bullous lesions are present (106). In fact, about $20 \%$ of patients present with non-bullous variants with excoriations, erythematous, or urticarial lesions (107). Nonbullous lesions also usually develop during a prodromal stage that may last for several months. Mucosal lesions, which occur in $15-20 \%$ of the BP patients, are associated with high disease severity and with absence of anti-BP230 antibodies (108).

BP180 is a collagen-type transmembrane glycoprotein of about 1,500 amino acids. It is a heterotrimer, consisting of a globular intracellular domain, a short transmembranous segment, and an extracellular C-terminal domain composed of 15 collagen repeats that are separated by 16 noncollagenous (NC) subdomains (109). The C-terminal domain forms a loop structure as it goes through the lamina lucida, spans the lamina densa, and then bends back into the lamina lucida (110). The 16th of the extracellular non-collagenous subdomains, NC16A, is the immunodominant region in BP (111). It is used in two ELISA systems $(47,48)$ (Figure 4), which on the one hand provide a sensitive and specific diagnostic tool for the routine diagnosis of BP and on the other hand are used to monitor the serum levels of anti-BP180 NC16A antibodies during the course of the disease (112). Alternatively, an IIF test using recombinant NC16A is widely available (77) (Figure 4). In most of the BP patients, autoantibodies are also directed against BP180epitopes outside the NC16A-domain (113). In the $10-15 \%$ of $\mathrm{BP}$ patients with no reactivity against NC16A, testing for those antibodies is recommended; however, no commercial assay is available so far. In addition to several recombinant fragments of the C-terminal part of BP180, the cell-derived $120 \mathrm{kDa}$ shed ectodomain present in the conditioned concentrated medium of cultures keratinocytes can be applied by immunoblotting for the detection of non-NC16A-reactive sera.

The major immunoglobulin class in BP is IgG. However, it has been shown that some patients also develop anti-BP180 IgA and IgE autoantibodies (114). In fact, most of the BP sera contain both IgG and IgA autoantibodies to BP180 (114, 115). Anti-BP180 IgE antibodies can be detected in $30-95 \%$ of the BP patients, and their detection corresponds to a high disease severity $(70,116)$.

BP230 is an intracellular component of the hemidesmosomal anchoring complex. It is a member of the plakin family. AntiBP230 IgG can be detected in the serum of $40-60 \%$ of the BP patients. Like for BP180, commercial ELISA systems are available for the detection of anti-BP230 antibodies, which can be used for the diagnosis of BP $(49,52)$ (Figure 4). $80 \%$ of the anti-BP230 autoantibodies found in the sera of BP patients most frequently target the globular C-terminal domain of BP230 that interacts with keratin filaments $(117,118)$. However, it remains unclear whether anti-BP230 antibodies are directly pathogenic (119). Also, unlike anti-BP180, serum levels of anti-BP230-antibodies do not correlate with the disease activity in BP patients (120). However, the detection of anti-BP230 autoantibodies remains a useful tool for the diagnosis of BP. Regarding this matter, the combined use of the BP180 and BP230 ELISA system provides a sensitivity of around $90 \%$ for the detection of circulating autoantibodies $(52,56,57)$.

\section{Pemphigoid Gestationis}

Pemphigoid gestationis (previously called herpes gestationis) is a dermatosis of pregnancy. It usually occurs during the third trimenon and less commonly, in the second trimenon or post partal period $(121,122)$. In contrast to BP, blisters are infrequent and usually small with predominating urticarial erythema frequently initiating around the umbilicus. Pemphigoid gestationis tends to recur in subsequent pregnancies, appearing earlier and with a more severe course. Serum autoantibodies to BP180 NC16A can be detected in $>95 \%$ of the patients by ELISA, having a sensitivity of 97\% (Figure 4) $(47,55)$. Recently, Sadik et al. detected NC16A reactivity in all of a large cohort of 65 pemphigoid gestationis sera using an IIF test based on the Biochip ${ }^{\circledR}$ mosaic technology (123). The main IgG subclasses are IgG1 and IgG3, explaining their high potential 


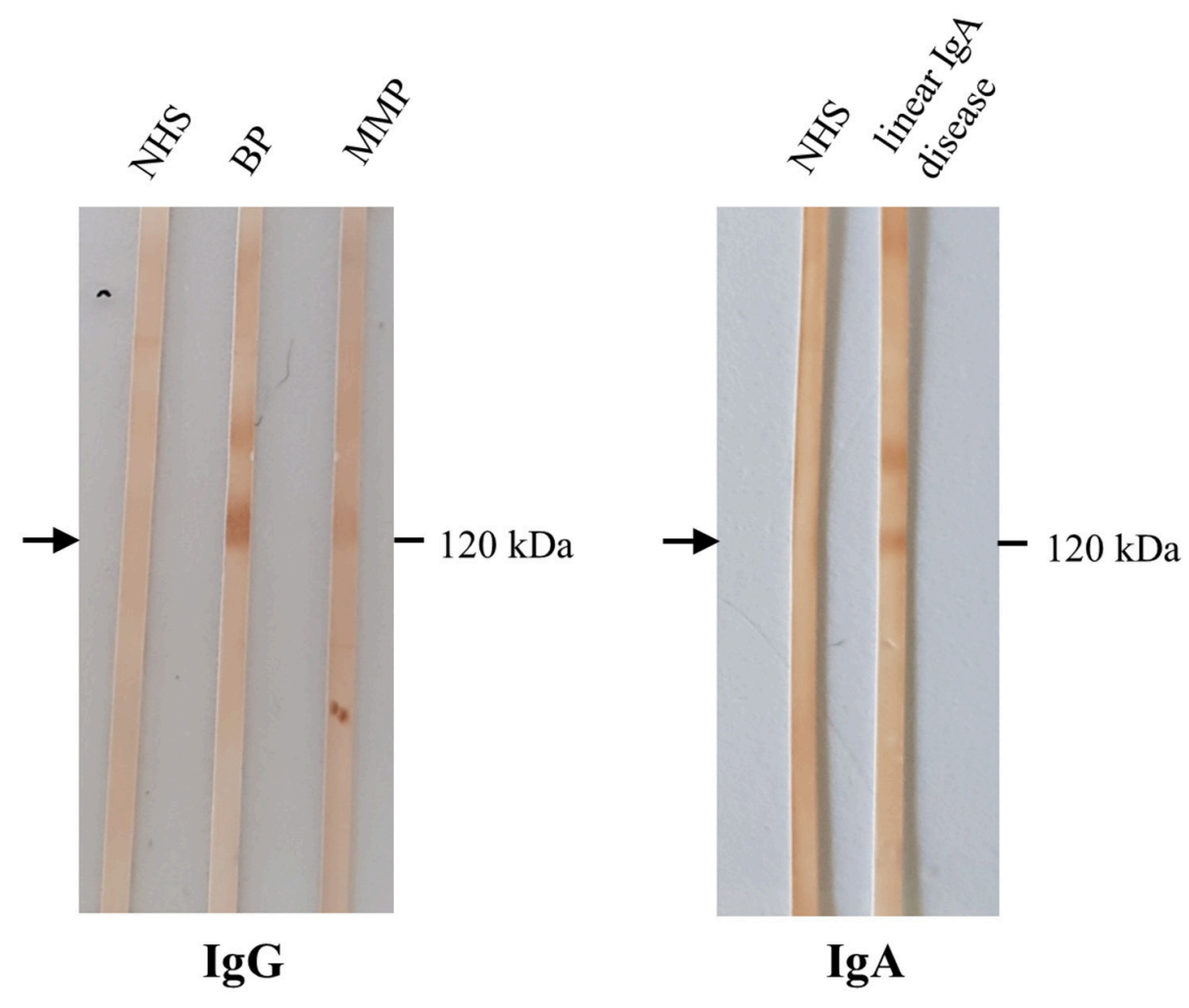

FIGURE 7 | Detection of IgG and IgA autoantibodies against LAD-1 by Western blotting with the concentrated conditioned medium of cultured human keratinocytes. Sera from patients with bullous pemphigoid (BP), mucous membrane pemphigoid (MMP), both without BP180 NC16A IgG by ELISA, showed IgG reactivity with the soluble ectodomain of BP180 (LAD-1; left, arrow). In serum of a patient with linear IgA disease, IgA antibodies against LAD-1 were present (right). NHS, normal human serum.

for the fixation of complement (124), a feature that is exploited by the IIF complement binding test that visualizes complementbinding anti-basement membrane antibodies (Figure 4). AntiBP230 reactivity is found in only $10 \%$ of sera (123).

\section{Mucous Membrane Pemphigoid}

MMP is defined as pemphigoid disease with predominant involvement of mucous membranes (125). It usually affects the mucous membranes of the mouth, eyes and genitals. Complications of the disease are conjunctival involvement and blindness, which may cause serious morbidity (Figure 8) (126, 127). Diagnosis is made by DIF microscopy of a perilesional biopsy, showing linear deposition of IgG and/or IgA and/or C3 along the DEJ (Figure 1) (126). In IIF microscopy, autoantibodies can only be detected in $50 \%$ of the MMP patients. Therefore, immunoprecipitation, Western blotting, and ELISA systems that employ cell-derived and recombinant proteins are essential diagnostic tests for MMP (Figure 4) (126). The main target antigen in MMP is BP180. However, in contrast to BP, the NC16A domain is only targeted in around 50\%. More commonly, the autoantibodies target C-terminal epitopes of BP180 such as LAD-1, the soluble ectodomain of BP180 (128, 129). Those autoantibodies can be detected by Western blotting, using the respective recombinant fragments of the C-terminus of BP180.
Both anti-BP180 IgG and IgA are predominant in anti-BP180type MMP. Therefore, it is necessary to test for both isotypes (Figure 4) (128). Further antigens in MMP are laminin 332 as well as $\alpha 6$ and $\beta 4$ integrin. Anti-laminin 332 antibodies can be detected in around $25 \%$ of the MMP-patients $(128,130)$. Laminin 332 , which was formerly known as epiligrin or laminin 5 , is a heterotrimeric protein composed of an $\alpha 3, \beta 3$, and $\gamma 2$ subunit. Anti-laminin 332 autoantibodies typically target the $\alpha 3$ chain (131). Since the presence of anti-laminin 332 autoantibodies is associated with development of malignancies in $25 \%$ (38, $132,133)$, screening for anti-laminin 332 reactivity is strongly recommended in every MMP patient and in case of positivity, a tumor search is mandatory. Unfortunately, no detection system for serum antibodies against laminin 332 is widely available. A sensitive and highly specific assay for serum anti-laminin 332 IgG based on the Biochip ${ }^{\circledR}$ mosaic technology has recently been developed (83) and will be commercialized later in 2018. Antibodies against $\alpha 6$ and $\beta 4$ integrin were detected in a few cases of oral and conjunctival MMP, respectively (134).

\section{Linear IgA Disease}

Linear IgA disease (LAD) is characterized by subepidermal blistering and linear deposition of predominantly IgA at the DEJ. The disease is characterized by its heterogenous phenotype that 

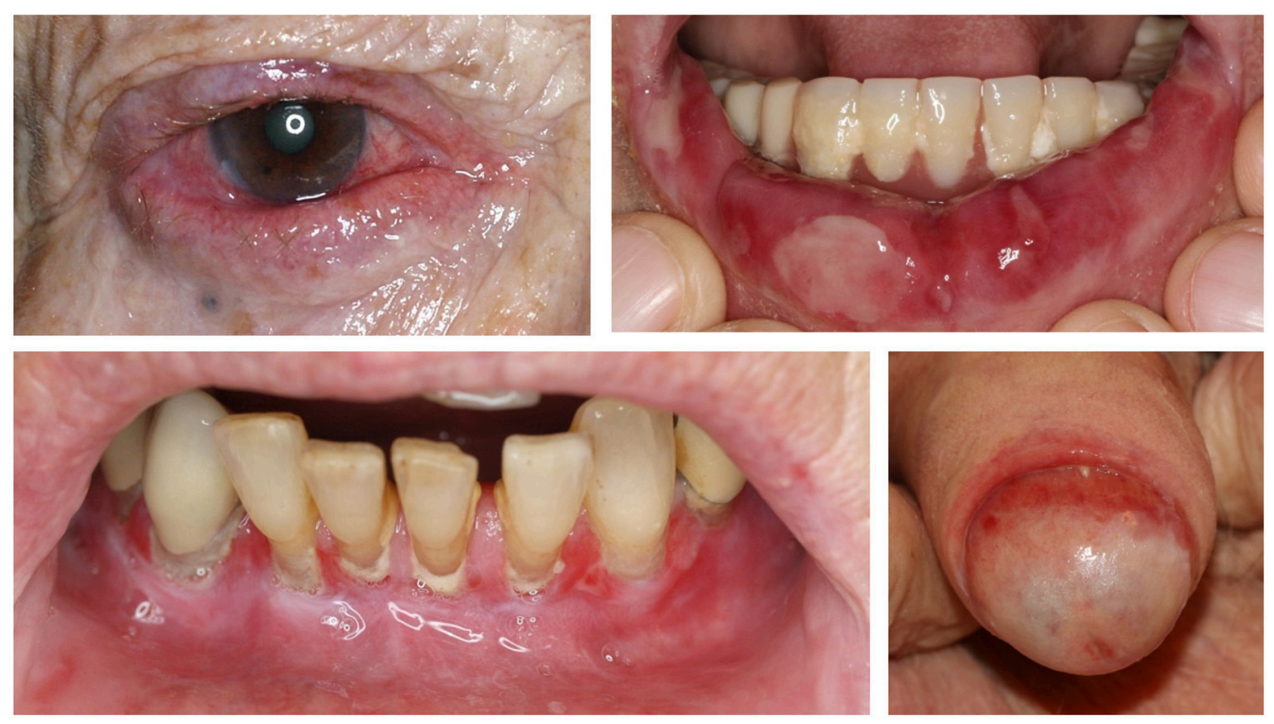

FIGURE 8 | Clinical findings in mucous membrane pemphigoid affecting the conjunctiva, lips, gingiva, and glans penis.

may be similar to other autoimmune skin blistering diseases. Mostly, the patients present with vesiculobullous lesions on the skin and adjacent mucous membranes $(135,136)$. Using DIF microscopy of a perilesional biopsy, a linear deposition of IgA autoantibodies along the DEJ can be detected (Figure 1). The autoantibodies bind to antigens of different molecular weights, including 97-, 120-, 180-, 200-, 230-, 280-, 285-, and 290-kDa proteins (137-139). According to the IIF findings, LAD can be divided into the lamina lucida type, where sera react with the epidermal side of salt-split skin and mostly with LAD-1 (140), and the sublamina densa type, that reveals serum antibodies against the dermal side of salt-split skin recognizing type VII collagen $(138,141,142)$ (Figure 4). Interestingly, a recent study showed that type VII collagen is also the most common target antigen in vancomycine-induced LAD (143). Due to sematic overlap, patients with IgA reactivity against type VII collagen can also be classified as IgA EBA, a view that is supported by a recent consensus of an international expert panel (144).

\section{Anti-P200/Anti-laminin $\gamma 1$ Pemphigoid}

Anti-p200 pemphigoid is an autoimmune skin blistering disease with antibodies directed against a $200 \mathrm{kDa}$ protein of the $\mathrm{DEJ}$ (145). Since laminin $\gamma 1$ is the target antigen in $90 \%$ of the cases, it is also known as anti-laminin $\gamma 1$ pemphigoid (65). Like $\mathrm{LAD}$, the clinical presentation is heterogeneous and in most of the cases resembles BP and the inflammatory variant of EBA. The lesions heal without scarring or milia formation. Mucous membranes are involved in about $20 \%$ of the patients (146). Palmoplantar involvement seems to be more frequent compared to BP and a high association with psoriasis is seen in Japanese patients with anti-laminin 332 pemphigoid $(146,147)$. Antibodies against p200 bind to the floor of the artificial blister of salt-split skin using IIF microscopy (Figure 4). They can be detected by Western blotting with extracts of human dermis
(Figure 6) (145). However, the preparation of those extracts is challenging and problematic. Therefore, an ELISA system was developed, using the recombinant C-terminus of laminin $\gamma 1$, with a sensitivity of around $70 \%$ and a specificity of nearly $99 \%$ (64).

\section{Epidermolysis Bullosa Acquisita}

EBA affects skin and, to less extent, mucous membranes and is characterized by autoantibodies against type VII collagen (Figure 2 right) $(31,148)$. There are two main clinical forms of EBA $(144,149,150)$. The mechanobullous form represents the classical form of EBA. It is clinically characterized by skin fragility, tense blisters, vesicles, and erosions on non-inflamed skin in trauma-prone sites. Lesions may heal with scarring and milia formation $(149,151)$. In about two thirds of EBA, the inflammatory variant develops resembling BP, MMP, or LAD $(149,152)$. The diagnostic gold standards are direct immunogold electron microscopy, a methods nowadays only performed for this purpose in handful of centers, and more conveniently, DIF microscopy (144). By latter method, diagnosis of EBA can be made when a $\mathrm{u}$-serrated binding pattern is present as detailed above (Figures 1, 3). Type VII collagen-specific autoantibodies are deposited at the floor of the artificial blister of salt-split human skin using IIF microscopy (Figure 2 right) and are mostly directed against the noncollagenous (NC)1 domain $(153,154)$. Autoantibodies can be detected via Western blotting, using an extract of the human dermis (Figure 6). Three assays for the diagnostic detection of serum IgG against type VII collagen are available; two ELISA system using the $\mathrm{NC1}$ domain or both the NC1 and NC2 domains as well as an IIF test based on the Biochip mosaic technology employing human cells that express the recombinant NC1 domain (Figure 4) (50, 51, 75). Antitype VII collagen ELISA values were shown to correlate with disease activity (155), thus, like in PV, PF, and BP, the respective 
ELISA systems are useful tools not only for the diagnosis of the disease but also to guide treatment decisions during the course of the diseases. Patients with predominant or exclusive IgA reactivity against type VII collagen are usually classified as IgA EBA following the consensus of an international expert panel $(144,149,152,156,157)$.

\section{Dermatitis Herpetiformis}

Dermatitis herpetiformis is an autoimmune disease that always occurs in combination with glutensensitive enteropathy (celiac disease). It is clinically characterized by grouped vesicles and papules and predominantly affects the elbows, buttocks, and knees $(146,147,149,158-160)$. The autoantigen is the epidermal transglutaminase, however antibodies against gliadin, endomysium, tissue transglutaminase (TG2), and epidermal transglutaminase (TG3) can be detected (161). The main antibody-subclass is IgA but can be $\operatorname{IgG}$ in some patients. In patients under treatment with dapsone or on gluten-restricted diet, autoantibodies against the epidermal transglutaminase are found more frequently than autoantibodies

\section{REFERENCES}

1. Kasperkiewicz M, Ellebrecht CT, Takahashi H, Yamagami J, Zillikens D, Payne AS, et al. Pemphigus. Nat Rev Dis Primer (2017) 3:17026. doi: $10.1038 /$ nrdp.2017.26

2. Schmidt E, Zillikens D. Pemphigoid diseases. Lancet Lond Engl. (2013) 381:320-32. doi: 10.1016/S0140-6736(12)61140-4

3. Schmidt E, Zillikens D. The diagnosis and treatment of autoimmune blistering skin diseases. Dtsch Arzteblatt Int. (2011) 108:399-405. doi: 10.3238/arztebl.2011.0405

4. Schmidt E, Zillikens D. Modern diagnosis of autoimmune blistering skin diseases. Autoimmun Rev. (2010) 10:84-9. doi: 10.1016/j.autrev.2010.08.007

5. Bertram F, Bröcker E-B, Zillikens D, Schmidt E. Prospective analysis of the incidence of autoimmune bullous disorders in Lower Franconia, Germany. J Dtsch Dermatol Ges J Ger Soc Dermatol. (2009) 7:434-40. doi: 10.1111/j.1610-0387.2008.06976.x

6. Marazza G, Pham HC, Schärer L, Pedrazzetti PP, Hunziker T, Trüeb $\mathrm{RM}$, et al. Incidence of bullous pemphigoid and pemphigus in Switzerland: a 2-year prospective study. Br J Dermatol. (2009) 161:861-8. doi: 10.1111/j.1365-2133.2009.09300.x

7. Joly P, Baricault S, Sparsa A, Bernard P, Bédane C, Duvert-Lehembre S, et al. Incidence and mortality of bullous pemphigoid in France. J Invest Dermatol. (2012) 132:1998-2004. doi: 10.1038/jid.2012.35

8. Försti A-K, Jokelainen J, Timonen M, Tasanen K. Increasing incidence of bullous pemphigoid in Northern Finland: a retrospective database study in Oulu University Hospital. Br J Dermatol. (2014) 171:1223-6. doi: 10.1111/bjd.13189

9. Langan SM, Smeeth L, Hubbard R, Fleming KM, Smith CJP, West J. Bullous pemphigoid and pemphigus vulgaris-incidence and mortality in the UK: population based cohort study. BMJ (2008) 337:a180. doi: 10.1136/bmj.a180

10. Thorslund K, Seifert O, Nilzén K, Grönhagen C. Incidence of bullous pemphigoid in Sweden 2005-2012: a nationwide population-based cohort study of 3761 patients. Arch Dermatol Res. (2017) 309:721-7. doi: 10.1007/s00403-017-1778-4

11. Bertram F, BrÃcker E-B, Zillikens D, Schmidt E. Prospektive Untersuchung der Inzidenz blasenbildender Autoimmundermatosen in Unterfranken. J Dtsch Dermatol Ges. (2009) 7:434-40. doi: 10.1111/j.1610-0387.2008.06976_supp.x

12. Försti A-K, Huilaja L, Schmidt E, Tasanen K. Neurological and psychiatric associations in bullous pemphigoid-more than skin deep? Exp Dermatol. (2017) 26:1228-34. doi: 10.1111/exd.13401 to tissue transglutaminase (162). The diagnosis is based on the DIF and IIF microscopy findings as well as commercial ELISA systems. Here, IgA (or IgG)-autoantibodies against the epidermal and tissue transglutaminase as well as the deaminated gliadin-analogous fusion (GAF) peptides can be detected (61, 162).

\section{AUTHOR CONTRIBUTIONS}

MW and ES performed the literature research, acquired and designed the figures and wrote the manuscript. DZ performed literature research and critically revised the manuscript.

\section{ACKNOWLEDGMENTS}

We thank Inge Atefi, Dr. Stephanie Freyher, and Marina Kongsbak-Reim, Lübeck, for technical assistance. This work was supported by grants from the Deutsche Forschungsgemeinschaft through CRU 303 Pemphigoid Diseases (to DZ and ES) and Excellence Cluster 306/2 Inflammation at Interfaces.

13. Ren Z, Hsu DY, Brieva J, Silverberg NB, Langan SM, Silverberg JI. Hospitalization, inpatient burden and comorbidities associated with bullous pemphigoid in the U.S.A. Br J Dermatol. (2017) 176:87-99. doi: $10.1111 /$ bjd.14821

14. Meyer N, Misery L. Geoepidemiologic considerations of auto-immune pemphigus. Autoimmun Rev. (2010) 9:A379-82. doi: 10.1016/j.autrev.2009. 10.009

15. Kridin K. Pemphigus group: overview, epidemiology, mortality, and comorbidities. Immunol Res. (2018) 66:255-70. doi: 10.1007/s12026-018-8986-7

16. Bastuji-Garin S, Souissi R, Blum L, Turki H, Nouira R, Jomaa B, et al. Comparative epidemiology of pemphigus in Tunisia and France: unusual incidence of pemphigus foliaceus in young Tunisian women. I Invest Dermatol. (1995) 104:302-405.

17. Culton DA, Qian Y, Li N, Rubenstein D, Aoki V, Filhio GH, et al. Advances in pemphigus and its endemic pemphigus foliaceus (Fogo Selvagem) phenotype: a paradigm of human autoimmunity. J Autoimmun. (2008) 31:311-24. doi: 10.1016/j.jaut.2008.08.003

18. Hübner F, Recke A, Zillikens D, Linder R, Schmidt E. Prevalence and age distribution of pemphigus and pemphigoid diseases in Germany. I Invest Dermatol. (2016) 136:2495-8. doi: 10.1016/j.jid.2016.07.013

19. Lever WF. Pemphigus: a historical study. Arch Dermatol Syphilol. (1942) 46:800. doi: 10.1001/archderm.1942.01500180020004

20. Lever WF. Pemphigus. Medicine (1953) 32:1-123.

21. Beutner EH, Jordon RE. Demonstration of skin antibodies in sera of pemphigus vulgaris patients by indirect immunofluorescent staining. Proc Soc Exp Biol Med. (1964) 117:505-10.

22. Jordon RE, Beutner EH, Witebsky E, Blumental G, Hale WL, Lever WF. Basement zone antibodies in bullous pemphigoid. JAMA (1967) 200:751-6.

23. Mihai S, Sitaru C. Immunopathology and molecular diagnosis of autoimmune bullous diseases. J Cell Mol Med. (2007) 11:462-81. doi: 10.1111/j.1582-4934.2007.00033.x

24. Anhalt GJ, Labib RS, Voorhees JJ, Beals TF, Diaz LA. Induction of pemphigus in neonatal mice by passive transfer of IgG from patients with the disease. N Engl J Med. (1982) 306:1189-96. doi: 10.1056/NEJM1982052030 62001

25. Liu Z, Diaz LA, Troy JL, Taylor AF, Emery DJ, Fairley JA, et al. A passive transfer model of the organ-specific autoimmune disease, bullous pemphigoid, using antibodies generated against the hemidesmosomal antigen, BP180. J Clin Invest. (1993) 92:2480-8. doi: 10.1172/JCI1 16856 
26. Lazarova Z, Hsu R, Yee C, Yancey KB. Antiepiligrin cicatricial pemphigoid represents an autoimmune response to subunits present in laminin 5 (alpha3beta3gamma2). Br J Dermatol. (1998) 139:791-7.

27. Nishie W, Sawamura D, Goto M, Ito K, Shibaki A, McMillan JR, et al. Humanization of autoantigen. Nat Med. (2007) 13:378-83. doi: $10.1038 / \mathrm{nm} 1496$

28. Schulze FS, Beckmann T, Nimmerjahn F, Ishiko A, Collin M, Köhl J, et al. Fc $\gamma$ receptors III and IV mediate tissue destruction in a novel adult mouse model of bullous pemphigoid. Am J Pathol. (2014) 184:2185-96. doi: 10.1016/j.ajpath.2014.05.007

29. Heppe EN, Tofern S, Schulze FS, Ishiko A, Shimizu A, Sina C, et al. Experimental laminin 332 mucous membrane pemphigoid critically involves C5aR1 and reflects clinical and immunopathological characteristics of the human disease. J Invest Dermatol. (2017) 137:1709-18. doi: 10.1016/j.jid.2017.03.037

30. Stanley JR, Amagai M. Pemphigus, bullous impetigo, and the staphylococcal scalded-skin syndrome. N Engl J Med. (2006) 355:1800-10. doi: 10.1056/NEJMra061111

31. Witte M, Koga H, Hashimoto T, Ludwig RJ, Bieber K. Discovering potential drug-targets for personalized treatment of autoimmune disorders-what we learn from epidermolysis bullosa acquisita. Expert Opin Ther Targets (2016) 20:985-98. doi: 10.1517/14728222.2016.1148686

32. Liu Z, Sui W, Zhao M, Li Z, Li N, Thresher R, et al. Subepidermal blistering induced by human autoantibodies to BP180 requires innate immune players in a humanized bullous pemphigoid mouse model. J Autoimmun. (2008) 31:331-8. doi: 10.1016/j.jaut.2008.08.009

33. Spindler V, Waschke J. Pemphigus-A disease of desmosome dysfunction caused by multiple mechanisms. Front Immunol. (2018) 9:136. doi: 10.3389/fimmu.2018.00136

34. Spindler V, Eming R, Schmidt E, Amagai M, Grando S, Jonkman MF, et al. Mechanisms causing loss of keratinocyte cohesion in pemphigus. J Invest Dermatol. (2018) 138:32-7. doi: 10.1016/j.jid.2017.06.022

35. Boraiy L, Fontao L. Michel's transport medium as an alternative to liquid nitrogen for PCR analysis of skin biopsy specimens. Dermatopathology (2014) 1:70-4. doi: 10.1159/000368347

36. Schmidt E, Goebeler M, Hertl M, Sárdy M, Sitaru C, Eming R, et al. S2k guideline for the diagnosis of pemphigus vulgaris/foliaceus and bullous pemphigoid. J Dtsch Dermatol Ges. (2015) 13:713-27. doi: $10.1111 /$ ddg. 12612

37. Vodegel RM, Jonkman MF, Pas HH, de Jong MCJM. U-serrated immunodeposition pattern differentiates type VII collagen targeting bullous diseases from other subepidermal bullous autoimmune diseases. $\mathrm{Br} \mathrm{J}$ Dermatol. (2004) 151:112-8. doi: 10.1111/j.1365-2133.2004.06006.x

38. Terra JB, Pas HH, Hertl M, Dikkers FG, Kamminga N, Jonkman MF. Immunofluorescence serration pattern analysis as a diagnostic criterion in antilaminin-332 mucous membrane pemphigoid: immunopathological findings and clinical experience in 10 Dutch patients. Br J Dermatol. (2011) 165:815-22. doi: 10.1111/j.1365-2133.2011.10474.x

39. Meijer JM, Atefi I, Diercks GFH, Vorobyev A, Zuiderveen J, Meijer HJ, et al. Serration pattern analysis for differentiating epidermolysis bullosa acquisita from other pemphigoid diseases. J Am Acad Dermatol. (2018) 78:754-9.e6. doi: 10.1016/j.jaad.2017.11.029

40. Lemcke S, Sokolowski S, Rieckhoff N, Buschtez M, Kaffka C, Winter-Keil A, et al. Automated direct immunofluorescence analyses of skin biopsies. $J$ Cutan Pathol. (2016) 43:227-35. doi: 10.1111/cup.12637

41. Sárdy M, Kostaki D, Varga R, Peris K, Ruzicka T. Comparative study of direct and indirect immunofluorescence and of bullous pemphigoid 180 and 230 enzyme-linked immunosorbent assays for diagnosis of bullous pemphigoid. J Am Acad Dermatol. (2013) 69:748-53. doi: 10.1016/j.jaad.2013.07.009

42. Ng PPL, Thng STG, Mohamed K, Tan SH. Comparison of desmoglein ELISA and indirect immunofluorescence using two substrates (monkey oesophagus and normal human skin) in the diagnosis of pemphigus. Australas J Dermatol. (2005) 46:239-41. doi: 10.1111/j.1440-0960.2005.00 191.x

43. Harman KE, Gratian MJ, Bhogal BS, Challacombe SJ, Black MM. The use of two substrates to improve the sensitivity of indirect immunofluorescence in the diagnosis of pemphigus. Br J Dermatol. (2000) 142:1135-9. doi: $10.1046 /$ j.1365-2133.2000.03538.x
44. Oyama N, Bhogal BS, Carrington P, Gratian MJ, Black MM. Human placental amnion is a novel substrate for detecting autoantibodies in autoimmune bullous diseases by immunoblotting. Br J Dermatol. (2003) 148:939-44. doi: 10.1046/j.1365-2133.2003.05316.x

45. Machado P, Michalaki H, Roche P, Gaucherand M, Thivolet J, Nicolas JF. Serological diagnosis of bullous pemphigoid (BP): comparison of the sensitivity of indirect immunofluorescence on salt-split skin to immunoblotting. Br J Dermatol (1992) 126:236-241.

46. Schmidt E, Dähnrich C, Rosemann A, Probst C, Komorowski L, Saschenbrecker S, et al. Novel ELISA systems for antibodies to desmoglein 1 and 3: correlation of disease activity with serum autoantibody levels in individual pemphigus patients. Exp Dermatol. (2010) 19:458-63. doi: 10.1111/j.1600-0625.2010.01069.x

47. Sitaru C, Dähnrich C, Probst C, Komorowski L, Blöcker I, Schmidt E, et al. Enzyme-linked immunosorbent assay using multimers of the 16th non-collagenous domain of the BP180 antigen for sensitive and specific detection of pemphigoid autoantibodies. Exp Dermatol. (2007) 16:770-7. doi: 10.1111/j.1600-0625.2007.00592.x

48. Kobayashi M, Amagai M, Kuroda-Kinoshita K, Hashimoto T, Shirakata Y, Hashimoto K, et al. BP180 ELISA using bacterial recombinant NC16a protein as a diagnostic and monitoring tool for bullous pemphigoid. $J$ Dermatol Sci. (2002) 30:224-32. doi: 10.1016/S0923-1811(02)00109-3

49. Yoshida M, Hamada T, Amagai M, Hashimoto K, Uehara R, Yamaguchi $\mathrm{K}$, et al. Enzyme-linked immunosorbent assay using bacterial recombinant proteins of human BP230 as a diagnostic tool for bullous pemphigoid. $J$ Dermatol Sci. (2006) 41:21-30. doi: 10.1016/j.jdermsci.2005.11.002

50. Komorowski L, Müller R, Vorobyev A, Probst C, Recke A, Jonkman MF, et al. Sensitive and specific assays for routine serological diagnosis of epidermolysis bullosa acquisita. J Am Acad Dermatol. (2013) 68:e89-95. doi: 10.1016/j.jaad.2011.12.032

51. Saleh MA, Ishii K, Kim Y-J, Murakami A, Ishii N, Hashimoto $\mathrm{T}$, et al. Development of $\mathrm{NC} 1$ and $\mathrm{NC} 2$ domains of type VII collagen ELISA for the diagnosis and analysis of the time course of epidermolysis bullosa acquisita patients. J Dermatol Sci. (2011) 62:169-75. doi: 10.1016/j.jdermsci.2011.03.003

52. Blöcker IM, Dähnrich C, Probst C, Komorowski L, Saschenbrecker S, Schlumberger W, et al. Epitope mapping of BP230 leading to a novel enzymelinked immunosorbent assay for autoantibodies in bullous pemphigoid. $\mathrm{Br} \mathrm{J}$ Dermatol (2012) 166:964-970. doi: 10.1111/j.1365-2133.2012.10820.x

53. Tampoia M, Giavarina D, Di Giorgio C, Bizzaro N. Diagnostic accuracy of enzyme-linked immunosorbent assays (ELISA) to detect anti-skin autoantibodies in autoimmune blistering skin diseases: a systematic review and meta-analysis. Autoimmun Rev. (2012) 12:121-6. doi: 10.1016/j.autrev.2012.07.006

54. Powell AM, Sakuma-Oyama Y, Oyama N, Albert S, Bhogal B, Kaneko F, et al. Usefulness of BP180 NC16a enzyme-linked immunosorbent assay in the serodiagnosis of pemphigoid gestationis and in differentiating between pemphigoid gestationis and pruritic urticarial papules and plaques of pregnancy. Arch Dermatol. (2005) 141:705-10. doi: 10.1001/archderm.141.6.705

55. Al Saif F, Jouen F, Hebert V, Chiavelli H, Darwish B, Duvert-Lehembre S, et al, French Study Group on Autoimmune Bullous Skin Diseases. Sensitivity and specificity of BP180 NC16A enzyme-linked immunosorbent assay for the diagnosis of pemphigoid gestationis. J Am Acad Dermatol. (2017) 76:560-2. doi: 10.1016/j.jaad.2016.09.030

56. Charneux J, Lorin J, Vitry F, Antonicelli F, Reguiai Z, Barbe C, et al. Usefulness of BP230 and BP180-NC16a enzyme-linked immunosorbent assays in the initial diagnosis of bullous pemphigoid: a retrospective study of 138 patients. Arch Dermatol. (2011) 147:286-91. doi: 10.1001/archdermatol.2011.23

57. Roussel A, Benichou J, Randriamanantany ZA, Gilbert D, Drenovska $\mathrm{K}$, Houivet E, et al. Enzyme-linked immunosorbent assay for the combination of bullous pemphigoid antigens 1 and 2 in the diagnosis of bullous pemphigoid. Arch Dermatol. (2011) 147:293-8. doi: 10.1001/archdermatol.2011.21

58. Ishii K, Amagai M, Hall RP, Hashimoto T, Takayanagi A, Gamou S, et al. Characterization of autoantibodies in pemphigus using antigenspecific enzyme-linked immunosorbent assays with baculovirus-expressed recombinant desmogleins. J Immunol. (1997) 159:2010-7. 
59. Harman KE, Seed PT, Gratian MJ, Bhogal BS, Challacombe SJ, Black MM. The severity of cutaneous and oral pemphigus is related to desmoglein 1 and 3 antibody levels. Br J Dermatol. (2001) 144:775-80. doi: 10.1046/j.1365-2133.2001.04132.x

60. Probst C, Schlumberger W, Stöcker W, Recke A, Schmidt E, Hashimoto $\mathrm{T}$, et al. Development of ELISA for the specific determination of autoantibodies against envoplakin and periplakin in paraneoplastic pemphigus. Clin Chim Acta (2009) 410:13-8. doi: 10.1016/j.cca.2009. 08.022

61. Kasperkiewicz M, Dähnrich C, Probst C, Komorowski L, Stöcker W, Schlumberger W, et al Novel assay for detecting celiac disease-associated autoantibodies in dermatitis herpetiformis using deamidated gliadinanalogous fusion peptides. J Am Acad Dermatol. (2012) 66:583-8. doi: 10.1016/j.jaad.2011.02.025

62. Müller R, Heber B, Hashimoto $T$, Messer G, Müllegger R, Niedermeier A, et al. Autoantibodies against desmocollins in European patients with pemphigus. Clin Exp Dermatol. (2009) 34:898-903. doi: 10.1111/j.1365-2230.2009.03241.x

63. Ishii N, Teye K, Fukuda S, Uehara R, Hachiya T, Koga H, et al. Antidesmocollin autoantibodies in nonclassical pemphigus. Br J Dermatol. (2015) 173:59-68. doi: 10.1111/bjd.13711

64. Groth S, Recke A, Vafia K, Ludwig RJ, Hashimoto T, Zillikens D, et al. Development of a simple enzyme-linked immunosorbent assay for the detection of autoantibodies in anti-p200 pemphigoid. Br J Dermatol. (2011) 164:76-82. doi: 10.1111/j.1365-2133.2010.10056.x

65. Dainichi T, Kurono S, Ohyama B, Ishii N, Sanzen N, Hayashi M, et al. Antilaminin gamma-1 pemphigoid. Proc Natl Acad Sci USA. (2009) 106:2800-5. doi: 10.1073/pnas.0809230106

66. Csorba K, Schmidt S, Florea F, Ishii N, Hashimoto T, Hertl M, et al. Development of an ELISA for sensitive and specific detection of $\operatorname{IgA}$ autoantibodies against BP180 in pemphigoid diseases. Orphanet J Rare Dis. (2011) 6:31. doi: 10.1186/1750-1172-6-31

67. Izumi K, Nishie W, Mai Y, Wada M, Natsuga K, Ujiie H, et al. Autoantibody Profile Differentiates between Inflammatory and noninflammatory bullous pemphigoid. J Invest Dermatol. (2016) 136:2201-10. doi: 10.1016/j.jid.2016.06.622

68. Bekou V, Thoma-Uszynski S, Wendler O, Uter W, Schwietzke S, Hunziker T, et al. Detection of laminin 5-specific auto-antibodies in mucous membrane and bullous pemphigoid sera by ELISA. J Invest Dermatol. (2005) 124:73240. doi: 10.1111/j.0022-202X.2005.23646.x

69. Bernard P, Antonicelli F, Bedane C, Joly P, Le Roux-Villet C, DuvertLehembre S, et al. Prevalence and clinical significance of anti-laminin 332 autoantibodies detected by a novel enzyme-linked immunosorbent assay in mucous membrane pemphigoid. JAMA Dermatol. (2013) 149:533-40. doi: 10.1001/jamadermatol.2013.1434

70. Hashimoto T, Ohzono A, Teye K, Numata S, Hiroyasu S, Tsuruta D, et al. Detection of IgE autoantibodies to BP180 and BP230 and their relationship to clinical features in bullous pemphigoid. Br J Dermatol. (2017) 177:141-51. doi: 10.1111/bjd.15114

71. van Beek N, Lüttmann N, Huebner F, Recke A, Karl I, Schulze FS, et al. Correlation of serum levels of $\mathrm{IgE}$ autoantibodies against BP180 with bullous pemphigoid disease activity. JAMA Dermatol. (2017) 153:30-8. doi: 10.1001/jamadermatol.2016.3357

72. Messingham KAN, Noe MH, Chapman MA, Giudice GJ, Fairley JA. A novel ELISA reveals high frequencies of BP180-specific IgE production in bullous pemphigoid. J Immunol Methods (2009) 346:18-25. doi: 10.1016/j.jim.2009.04.013

73. Di Zenzo G, Thoma-Uszynski S, Fontao L, Calabresi V, Hofmann SC, Hellmark T, et al. Multicenter prospective study of the humoral autoimmune response in bullous pemphigoid. Clin Immunol. (2008) 128:415-26. doi: 10.1016/j.clim.2008.04.012

74. Hofmann S, Thoma-Uszynski S, Hunziker T, Bernard P, Koebnick C, Stauber A, et al. Severity and phenotype of bullous pemphigoid relate to autoantibody profile against the $\mathrm{NH} 2-$ and $\mathrm{COOH}$-terminal regions of the BP180 ectodomain. J Invest Dermatol. (2002) 119:1065-73. doi: 10.1046/j.1523-1747.2002.19529.x

75. van Beek N, Dähnrich C, Johannsen N, Lemcke S, Goletz S, Hübner F, et al. Prospective studies on the routine use of a novel multivariant enzyme-linked immunosorbent assay for the diagnosis of autoimmune bullous diseases. $J$ Am Acad Dermatol. (2017) 76:889-94.e5. doi: 10.1016/j.jaad.2016.11.002

76. Horváth ON, Varga R, Kaneda M, Schmidt E, Ruzicka T, Sárdy M. Diagnostic performance of the "MESACUP anti-Skin profile TEST." Eur J Dermatol. (2016) 26:56-63. doi: 10.1684/ejd.2015.2692

77. van Beek N, Rentzsch K, Probst C, Komorowski L, Kasperkiewicz M, Fechner $\mathrm{K}$, et al. Serological diagnosis of autoimmune bullous skin diseases: prospective comparison of the BIOCHIP mosaic-based indirect immunofluorescence technique with the conventional multi-step single test strategy. Orphanet J Rare Dis. (2012) 7:49. doi: 10.1186/1750-117 2-7-49

78. Tampoia M, Zucano A, Villalta D, Antico A, Bizzaro N. Anti-skin specific autoantibodies detected by a new immunofluorescence multiplex biochip method in patients with autoimmune bullous diseases. Dermatology (2012) 225:37-44. doi: 10.1159/000339776

79. Russo I, Saponeri A, Peserico A, Alaibac M. The use of biochip immunofluorescence microscopy for the diagnosis of Pemphigus vulgaris. Acta Histochem. (2014) 116:713-6. doi: 10.1016/j.acthis.2013.12.012

80. Xuan RR, Yang A, Murrell DF. New biochip immunofluorescence test for the serological diagnosis of pemphigus vulgaris and foliaceus: a review of the literature. Int J Womens Dermatol. (2018) 4:102-8. doi: 10.1016/j.ijwd.2017.10.001

81. Marzano AV, Cozzani E, Biasin M, Russo I, Alaibac M. The use of Biochip immunofluorescence microscopy for the serological diagnosis of epidermolysis bullosa acquisita. Arch Dermatol Res. (2016) 308:273-6. doi: 10.1007/s00403-016-1632-0

82. Mindorf S, Dettmann IM, Krüger S, Fuhrmann T, Rentzsch K, Karl I, et al. Routine detection of serum antidesmocollin autoantibodies is only useful in patients with atypical pemphigus. Exp Dermatol. (2017) 26:1267-70. doi: $10.1111 /$ exd.13409

83. Goletz S, Probst C, Komorowski L, Schlumberger W, Fechner K, van Beek N, et al. Sensitive and specific assay for the serological diagnosis of anti-laminin 332 mucous membrane pemphigoid. Br J Dermatol. (2018) doi: 10.1111/bjd.17202. [Epub ahead of print].

84. Zimmermann J, Bahmer F, Rose C, Zillikens D, Schmidt E. Clinical and immunopathological spectrum of paraneoplastic pemphigus. J Dtsch Dermatol Ges. (2010) 8:598-606. doi: 10.1111/j.1610-0387.2010.07380.x

85. Grootenboer-Mignot S, Descamps V, Picard-Dahan C, NicaiseRoland P, Prost-Squarcioni C, Leroux-Villet C, et al. Place of human amniotic membrane immunoblotting in the diagnosis of autoimmune bullous dermatoses. Br J Dermatol. (2010) 162:743-50. doi: $10.1111 / j .1365-2133.2009 .09566 . x$

86. Rashid KA, Stern JNH, Ahmed AR. Identification of an epitope within human integrin alpha 6 subunit for the binding of autoantibody and its role in basement membrane separation in oral pemphigoid. J Immunol. (2006) 176:1968-77. doi: 10.4049/jimmunol.176.3.1968

87. Vodegel RM, Kiss M, Cjm De Jong M, Pas HH, Altmayer A, Molnar K, et al. The use of skin substrates deficient in basement membrane molecules for the diagnosis of subepidermal autoimmune bullous disease. Eur J Dermatol EJD. (1998) 8:83-5.

88. van Beek N, Knuth-Rehr D, Altmeyer P, Assaf C, Babilas P, Bayerl C, et al. Diagnostics of autoimmune bullous diseases in German dermatology departments. J Dtsch Dermatol Ges. (2012) 10:492-9. doi: $10.1111 / j .1610-0387.2011 .07840 . x$

89. Uzun S, Durdu M. The specificity and sensitivity of nikolskiy sign in the diagnosis of pemphigus. J Am Acad Dermatol. (2006) 54:411-5. doi: 10.1016/j.jaad.2005.10.019

90. James KA, Culton DA, Diaz LA. Diagnosis and clinical features of pemphigus foliaceus. Dermatol Clin. (2011) 29:405-12. doi: 10.1016/j.det.2011.03.012

91. Stanley JR, Koulu L, Klaus-Kovtun V, Steinberg MS. A monoclonal antibody to the desmosomal glycoprotein desmoglein I binds the same polypeptide as human autoantibodies in pemphigus foliaceus. J Immunol. (1986) 136:1227-30.

92. Kárpáti S, Amagai M, Prussick R, Stanley JR. Pemphigus vulgaris antigen is a desmosomal desmoglein. Dermatolology (1994) 189 (Suppl. 1):24-6. doi: $10.1159 / 000246923$

93. Anhalt GJ. Paraneoplastic pemphigus. Adv Dermatol. (1997) 12:77-96; discussion 97. 
94. Anhalt GJ. Paraneoplastic pemphigus. J Invest Dermatol Symp Proc. (2004) 9:29-33. doi: 10.1111/j.1087-0024.2004.00832.x

95. Czernik A, Wieczorek M. Paraneoplastic pemphigus: a short review. Clin Cosmet Investig Dermatol. (2016) 9:291-5. doi: 10.2147/CCID.S100802

96. Akel R, Fakhri G, Salem R, Boulos F, Habib K, Tfayli A. Paraneoplastic pemphigus as a first manifestation of an intra-abdominal follicular dendritic cell sarcoma: rare case and review of the literature. Case Rep Oncol. (2018) 353-9. doi: 10.1159/000489602

97. Adaszewska A, Ishii N, Dwilewicz-Trojaczek J, Wozniak K, Hashimoto T, Kowalewski C. Paraneoplastic pemphigus with anti-desmocollin 3 autoantibodies and chronic lymphocytic leukemia. Adv Dermatol Allergol. (2018) 35:113-5. doi: 10.5114/ada.2018.73171

98. Nikolskaia OV, Nousari CH, Anhalt GJ. Paraneoplastic pemphigus in association with Castleman's disease. Br J Dermatol. (2003) 149:1143-51. doi: 10.1111/j.1365-2133.2003.05659.x

99. Tsuchisaka A, Numata S, Teye K, Natsuaki Y, Kawakami T, Takeda Y, et al. Epiplakin is a paraneoplastic pemphigus autoantigen and related to bronchiolitis obliterans in Japanese patients. J Invest Dermatol. (2016) 136:399-408. doi: 10.1038/JID.2015.408

100. Schepens I, Jaunin F, Begre N, Läderach U, Marcus K, Hashimoto T, et al. The protease inhibitor alpha-2-macroglobulin-like-1 is the p170 antigen recognized by paraneoplastic pemphigus autoantibodies in human. PLoS ONE (2010) 5:e12250. doi: 10.1371/journal.pone.0012250

101. Zhang B, Zheng $\mathrm{R}$, Wang J, Bu D, Zhu X. Epitopes in the linker subdomain region of envoplakin recognized by autoantibodies in paraneoplastic pemphigus patients. J Invest Dermatol. (2006) 126:832-40. doi: $10.1038 /$ sj.jid.5700198

102. Nagata Y, Karashima T, Watt FM, Salmhofer W, Kanzaki T, Hashimoto T. Paraneoplastic pemphigus sera react strongly with multiple epitopes on the various regions of envoplakin and periplakin, except for the c-terminal homologous domain of periplakin. J Invest Dermatol. (2001) 116:556-63. doi: 10.1046/j.1523-1747.2001.01263.x

103. Stanley JR, Hawley-Nelson P, Yuspa SH, Shevach EM, Katz SI. Characterization of bullous pemphigoid antigen: a unique basement membrane protein of stratified squamous epithelia. Cell (1981) 24:897-903.

104. Schwieger-Briel A, Moellmann C, Mattulat B, Schauer F, Kiritsi D, Schmidt E, et al. Bullous pemphigoid in infants: characteristics, diagnosis and treatment. Orphanet J Rare Dis. (2014) 9:185. doi: 10.1186/s13023-014-0185-6

105. Kippes W, Schmidt E, Roth A, Rzany B, Bröcker EB, Zillikens D. Immunopathologic changes in 115 patients with bullous pemphigoid. Hautarzt Z Dermatol Venerol Verwandte Geb. (1999) 50:866-72.

106. Schmidt E, della Torre R, Borradori L. Clinical features and practical diagnosis of bullous pemphigoid. Dermatol Clin. (2011) 29:427-38. doi: 10.1016/j.det.2011.03.010

107. della Torre R, Combescure C, Cortés B, Marazza G, Beltraminelli H, Naldi L, et al. Clinical presentation and diagnostic delay in bullous pemphigoid: a prospective nationwide cohort. Br J Dermatol. (2012) 167:1111-7. doi: 10.1111/j.1365-2133.2012.11108.x

108. Clapé A, Muller C, Gatouillat G, Le Jan S, Barbe C, Pham B-N, et al. Mucosal involvement in bullous pemphigoid is mostly associated with disease severity and to absence of anti-BP230 autoantibody. Front Immunol. (2018) 9:479. doi: 10.3389/fimmu.2018.00479

109. Giudice GJ, Emery DJ, Diaz LA. Cloning and primary structural analysis of the bullous pemphigoid autoantigen BP180. J Invest Dermatol. (1992) 99:243-50.

110. Masunaga T, Shimizu H, Yee C, Borradori L, Lazarova Z, Nishikawa T, et al. The extracellular domain of BPAG2 localizes to anchoring filaments and its carboxyl terminus extends to the lamina densa of normal human epidermal basement membrane. J Invest Dermatol. (1997) 109:200-6.

111. Zillikens D, Rose PA, Balding SD, Liu Z, Olague-Marchan M, Diaz LA, et al. Tight clustering of extracellular BP180 epitopes recognized by bullous pemphigoid autoantibodies. J Invest Dermatol. (1997) 109:573-9.

112. Schmidt E, Obe K, Bröcker EB, Zillikens D. Serum levels of autoantibodies to BP180 correlate with disease activity in patients with bullous pemphigoid. Arch Dermatol. (2000) 136:174-8. doi: 10.1001/archderm.136. 2.174

113. Di Zenzo G, Grosso F, Terracina M, Mariotti F, De Pità O, Owaribe K, et al. Characterization of the anti-BP180 autoantibody reactivity profile and epitope mapping in bullous pemphigoid patients. J Invest Dermatol. (2004) 122:103-10. doi: 10.1046/j.0022-202X.2003.22126.x

114. Horváth B, Niedermeier A, Podstawa E, Müller R, Hunzelmann $\mathrm{N}$, Kárpáti $\mathrm{S}$, et al. IgA autoantibodies in the pemphigoids and linear IgA bullous dermatosis. Exp Dermatol. (2010) 19:648-53. doi: $10.1111 /$ j.1600-0625.2010.01080.x

115. Kromminga A, Scheckenbach C, Georgi M, Hagel C, Arndt R, Christophers E, et al. Patients with bullous pemphigoid and linear IgA disease show a dual IgA and IgG autoimmune response to BP180. J Autoimmun. (2000) 15:293-300. doi: 10.1006/jaut.2000.0437

116. van Beek N, Schulze FS, Zillikens D, Schmidt E. IgE-mediated mechanisms in bullous pemphigoid and other autoimmune bullous diseases. Expert Rev Clin Immunol. (2016) 12:267-77. doi: 10.1586/1744666X.2016.1123092

117. Skaria M, Jaunin F, Hunziker T, Riou S, Schumann H, Bruckner-Tuderman $\mathrm{L}$, et al. IgG autoantibodies from bullous pemphigoid patients recognize multiple antigenic reactive sites located predominantly within the $\mathrm{B}$ and C subdomains of the COOH-terminus of BP230. J Invest Dermatol. (2000) 114:998-1004. doi: 10.1046/j.1523-1747.2000.00893.x

118. Hamada T, Nagata Y, Tomita M, Salmhofer W, Hashimoto T. Bullous pemphigoid sera react specifically with various domains of BP230, most frequently with C-terminal domain, by immunoblot analyses using bacterial recombinant proteins covering the entire molecule. Exp Dermatol. (2001) 10:256-63. doi: 10.1034/j.1600-0625.2001.100405.x

119. Hayakawa T, Teye K, Hachiya T, Uehara R, Hashiguchi M, Kawakami T, et al. Clinical and immunological profiles of anti-BP230-type bullous pemphigoid: restriction of epitopes to the C-terminal domain of BP230, shown by novel ELISAs of BP230-domain specific recombinant proteins. Eur J Dermatol. 26:155-63. doi: 10.1684/ejd.2015.2719

120. Daneshpazhooh M, Ghiasi M, Lajevardi V, Nasiri N, Balighi K, Teimourpour A, et al. BPDAI and ABSIS correlate with serum anti-BP180 NC16A IgG but not with anti-BP230 IgG in patients with bullous pemphigoid. Arch Dermatol Res. (2018) 310:255-9. doi: 10.1007/s00403-018-1817-9

121. Intong LRA, Murrell DF. Pemphigoid gestationis: pathogenesis and clinical features. Dermatol Clin. (2011) 29:447-52. doi: 10.1016/j.det.2011.03.002

122. Huilaja L, Mäkikallio K, Tasanen K. Gestational pemphigoid. Orphanet J Rare Dis. (2014) 9:136. doi: 10.1186/s13023-014-0136-2

123. Sadik CD, Pas HH, Bohlmann MK, Mousavi S, Benoit S, Sárdy $\mathrm{M}$, et al. Value of BIOCHIP technology in the serological diagnosis of pemphigoid gestationis. Acta Derm Venereol. (2017) 97:128-30. doi: 10.2340/00015555-2460

124. Chimanovitch I, Schmidt E, Messer G, Döpp R, Partscht K, Bröcker EB, et al. IgG1 and IgG3 are the major immunoglobulin subclasses targeting epitopes within the NC16A domain of BP180 in pemphigoid gestationis. $J$ Invest Dermatol. (1999) 113:140-2. doi: 10.1046/j.1523-1747.1999.00622.x

125. Chan LS, Ahmed AR, Anhalt GJ, Bernauer W, Cooper KD, Elder $\mathrm{MJ}$, et al. The first international consensus on mucous membrane pemphigoid: definition, diagnostic criteria, pathogenic factors, medical treatment, and prognostic indicators. Arch Dermatol. (2002) 138:370-9. doi: 10.1001/archderm.138.3.370

126. Holtsche MM, Zillikens D, Schmidt E. Mucous membrane pemphigoid. Hautarzt Z Dermatol Venerol Verwandte Geb. (2018) 69:67-83. doi: 10.1007/s00105-017-4089-y

127. Witte M, Zillikens D, Shimanovich I. Intravenous immunoglobulins for rituximab-resistant mucous membrane pemphigoid. J Eur Acad Dermatol Venereol. (2018) 32:e321-4. doi: 10.1111/jdv.14873

128. Schmidt E, Skrobek C, Kromminga A, Hashimoto T, Messer G, Bröcker EB, et al. Cicatricial pemphigoid: IgA and IgG autoantibodies target epitopes on both intra- and extracellular domains of bullous pemphigoid antigen 180. Br J Dermatol. (2001) 145:778-83. doi: 10.1046/j.1365-2133.2001. 04471.x

129. Oyama N, Setterfield JF, Powell AM, Sakuma-Oyama Y, Albert S, Bhogal BS, et al. Bullous pemphigoid antigen II (BP180) and its soluble extracellular domains are major autoantigens in mucous membrane pemphigoid: the pathogenic relevance to HLA class II alleles and disease severity. $\mathrm{Br} J$ Dermatol. (2006) 154:90-8. doi: 10.1111/j.1365-2133.2005.06998.x

130. Domloge-Hultsch N, Gammon WR, Briggaman RA, Gil SG, Carter WG, Yancey KB. Epiligrin, the major human keratinocyte integrin ligand, is a target in both an acquired autoimmune and an inherited 
subepidermal blistering skin disease. J Clin Invest. (1992) 90:1628-33. doi: $10.1172 /$ JCI116033

131. Kirtschig G, Marinkovich MP, Burgeson RE, Yancey KB. Anti-basement membrane autoantibodies in patients with anti-epiligrin cicatricial pemphigoid bind the alpha subunit of laminin 5. J Invest Dermatol. (1995) 105:543-8.

132. Egan CA, Lazarova Z, Darling TN, Yee C, Coté T, Yancey KB. Anti-epiligrin cicatricial pemphigoid and relative risk for cancer. Lancet Lond Engl. (2001) 357:1850-1. doi: 10.1016/S0140-6736(00)04971-0

133. Leverkus M, Schmidt E, Lazarova Z, Bröcker EB, Yancey KB, Zillikens D. Antiepiligrin cicatricial pemphigoid: an underdiagnosed entity within the spectrum of scarring autoimmune subepidermal bullous diseases? Arch Dermatol. (1999) 135:1091-8.

134. Rashid KA, Gürcan HM, Ahmed AR. Antigen specificity in subsets of mucous membrane pemphigoid. J Invest Dermatol. (2006) 126:2631-6. doi: 10.1038/sj.jid.5700465

135. Kasperkiewicz M, Meier M, Zillikens D, Schmidt E. Linear IgA disease: successful application of immunoadsorption and review of the literature. Dermatology (2010) 220:259-63. doi: 10.1159/000279318

136. Mintz EM, Morel KD. Clinical features, diagnosis, and pathogenesis of chronic bullous disease of childhood. Dermatol Clin. (2011) 29:459-62. doi: 10.1016/j.det.2011.03.022

137. Wojnarowska F, Whitehead P, Leigh IM, Bhogal BS, Black MM. Identification of the target antigen in chronic bullous disease of childhood and linear IgA disease of adults. Br J Dermatol. (1991) 124:157-62.

138. Marinkovich MP, Taylor TB, Keene DR, Burgeson RE, Zone JJ. LAD-1, the linear IgA bullous dermatosis autoantigen, is a novel $120-\mathrm{kDa}$ anchoring filament protein synthesized by epidermal cells. J Invest Dermatol. (1996) 106:734-8.

139. Zone JJ, Taylor TB, Meyer LJ, Petersen MJ. The $97 \mathrm{kDa}$ linear IgA bullous disease antigen is identical to a portion of the extracellular domain of the $180 \mathrm{kDa}$ bullous pemphigoid antigen, BPAg2. J Invest Dermatol. (1998) 110:207-10. doi: 10.1046/j.1523-1747.1998.00129.x

140. Willsteed E, Bhogal BS, Black MM, McKee P, Wojnarowska F. Use of $1 \mathrm{M}$ $\mathrm{NaCl}$ split skin in the indirect immunofluorescence of the linear IgA bullous dermatoses. J Cutan Pathol. (1990) 17:144-8.

141. Zillikens D, Herzele K, Georgi M, Schmidt E, Chimanovitch I, Schumann H, et al. Autoantibodies in a subgroup of patients with linear IgA disease react with the NC16A domain of BP1801. J Invest Dermatol. (1999) 113:947-53. doi: 10.1046/j.1523-1747.1999.00808.x

142. Tsuchisaka A, Ohara K, Ishii N, Nguyen NT, Marinkovich MP, Hashimoto T. Type VII collagen is the major autoantigen for sublamina densatype linear IgA bullous dermatosis. J Invest Dermatol. (2015) 135:626-9. doi: 10.1038/jid.2014.381

143. Yamagami J, Nakamura Y, Nagao K, Funakoshi T, Takahashi H, Tanikawa A, et al. Vancomycin mediates IgA autoreactivity in drug-induced linear iga bullous dermatosis. J Invest Dermatol. (2018) 138:1473-80. doi: 10.1016/j.jid.2017.12.035

144. Prost-Squarcioni C, Caux F, Schmidt E, Jonkman MF, Vassileva S, Kim SC, et al. International bullous diseases group: consensus on diagnostic criteria for epidermolysis bullosa acquisita. Br J Dermatol. (2017) 179:30-41. doi: 10.1111/bjd.16138

145. Zillikens D, Kawahara Y, Ishiko A, Shimizu H, Mayer J, Rank CV, et al. A novel subepidermal blistering disease with autoantibodies to a 200$\mathrm{kDa}$ antigen of the basement membrane zone. J Invest Dermatol. (1996) 106:1333-8.

146. Goletz S, Hashimoto T, Zillikens D, Schmidt E. Anti-p200 pemphigoid. J Am Acad Dermatol. (2014) 71:185-91. doi: 10.1016/j.jaad.2014.02.036

147. Dainichi T, Koga H, Tsuji T, Ishii N, Ohyama B, Ueda A, et al. From antip200 pemphigoid to anti-laminin gammal pemphigoid. J Dermatol. (2010) 37:231-8. doi: 10.1111/j.1346-8138.2009.00793.x

148. Woodley DT, Briggaman RA, O'Keefe EJ, Inman AO, Queen LL, Gammon WR. Identification of the skin basement-membrane autoantigen in epidermolysis bullosa acquisita. N Engl J Med. (1984) 310:1007-13. doi: 10.1056/NEJM198404193101602

149. Vorobyev A, Ludwig RJ, Schmidt E. Clinical features and diagnosis of epidermolysis bullosa acquisita. Expert Rev Clin Immunol. (2017) 13:157-69. doi: 10.1080/1744666X.2016.1221343
150. Ludwig RJ. Clinical presentation, pathogenesis, diagnosis, and treatment of epidermolysis bullosa acquisita. ISRN Dermatol. (2013) 2013:812029. doi: 10.1155/2013/812029

151. Roenigk HH, Ryan JG, Bergfeld WF. Epidermolysis bullosa acquisita. Report of three cases and review of all published cases. Arch Dermatol. (1971) 103:1-10.

152. Buijsrogge JJA, Diercks GFH, Pas HH, Jonkman MF. The many faces of epidermolysis bullosa acquisita after serration pattern analysis by direct immunofluorescence microscopy. Br J Dermatol. (2011) 165:92-8. doi: 10.1111/j.1365-2133.2011.10346.x

153. Lapiere JC, Woodley DT, Parente MG, Iwasaki T, Wynn KC, Christiano AM, et al. Epitope mapping of type VII collagen. Identification of discrete peptide sequences recognized by sera from patients with acquired epidermolysis bullosa. J Clin Invest. (1993) 92:1831-9. doi: 10.1172/JCI116774

154. Ishii N, Yoshida M, Hisamatsu Y, Ishida-Yamamoto A, Nakane $\mathrm{H}$, Iizuka $\mathrm{H}$, et al. Epidermolysis bullosa acquisita sera react with distinct epitopes on the NC1 and NC2 domains of type VII collagen: study using immunoblotting of domain-specific recombinant proteins and postembedding immunoelectron microscopy. $\mathrm{Br}$ J Dermatol. (2004) 150:843-51. doi: $10.1111 /$ j.1365-2133.2004.0 5933.x

155. Kim JH, Kim YH, Kim S, Noh EB, Kim S-E, Vorobyev A, et al. Serum levels of anti-type VII collagen antibodies detected by enzymelinked immunosorbent assay in patients with epidermolysis bullosa acquisita are correlated with the severity of skin lesions. J Eur Acad Dermatol Venereol. (2013) 27:e224-30. doi: 10.1111/j.1468-3083.2012.0 4617.x

156. Cox NH, Bearn MA, Herold J, Ainsworth G, Liu C. Blindness due to the IgA variant of epidermolysis bullosa acquisita, and treatment with osteo-odonto-keratoprosthesis. Br J Dermatol. (2007) 156:775-7. doi: 10.1111/j.1365-2133.2006.07739.x

157. Vodegel RM, de Jong MCJM, Pas HH, Jonkman MF. IgA-mediated epidermolysis bullosa acquisita: two cases and review of the literature. J Am Acad Dermatol. (2002) 47:919-25. doi: 10.1067/mjd.2002.1 25079

158. Bonciolini V, Bonciani D, Verdelli A, D'Errico A, Antiga E, Fabbri $\mathrm{P}$, et al. Newly described clinical and immunopathological feature of dermatitis herpetiformis. Clin Dev Immunol. (2012) 2012:967974. doi: 10.1155/2012/967974

159. Bolotin D, Petronic-Rosic V. Dermatitis herpetiformis. Part I. epidemiology, pathogenesis, and clinical presentation. J Am Acad Dermatol. (2011) 64:1017-24. doi: 10.1016/j.jaad.2010.09.777

160. Bolotin D, Petronic-Rosic V. Dermatitis herpetiformis. Part II. diagnosis, management, and prognosis. J Am Acad Dermatol. (2011) 64:1027-33. doi: 10.1016/j.jaad.2010.09.776

161. Sárdy M, Kárpáti S, Merkl B, Paulsson M, Smyth N. Epidermal transglutaminase (TGase 3) is the autoantigen of dermatitis herpetiformis. J Exp Med. (2002) 195:747-757. doi: 10.1084/jem.20011299

162. Rose C, Armbruster FP, Ruppert J, Igl B-W, Zillikens D, Shimanovich I. Autoantibodies against epidermal transglutaminase are a sensitive diagnostic marker in patients with dermatitis herpetiformis on a normal or glutenfree diet. J Am Acad Dermatol. (2009) 61:39-43. doi: 10.1016/j.jaad.2008. 12.037

Conflict of Interest Statement: DZ and ES have a scientific cooperation with Euroimmun, Lübeck.

The remaining author declares that the research was conducted in the absence of any commercial or financial relationships that could be construed as a potential conflict of interest.

Copyright (c) 2018 Witte, Zillikens and Schmidt. This is an open-access article distributed under the terms of the Creative Commons Attribution License (CC BY). The use, distribution or reproduction in other forums is permitted, provided the original author(s) and the copyright owner(s) are credited and that the original publication in this journal is cited, in accordance with accepted academic practice. No use, distribution or reproduction is permitted which does not comply with these terms. 